\title{
CLINICAL FEATURES OF LEFT ATRIAL MYXOMA
}

\author{
BY \\ J. F. GOODWIN, C. A. STANFIELD,* R. E. STEINER, H. H. BENTALL, \\ H. M. SAYED, $\dagger$ V. R. BLOOM, AND M. B. BISHOP + \\ From the Departments of Medicine, Radiodiagnosis, and Surgery, Postgraduate Medical School and \\ Hammersmith Hospital, London
}

(RECEIVED FOR PUBLICATION AUGUST 17, 1961)

Myxoma of the left atrium is the commonest primary cardiac neoplasm and numerous cases have been reported (Leach, 1947 ; Prichard, 1951). Criteria suggested for the diagnosis usually emphasize the similarity to mitral stenosis, the importance of postural changes in symptoms and signs, and the occurrence of syncope, arrhythmia, persistent heart failure, and embolic phenomena.

Left atrial myxomas have been confused with inflammatory disease, such as lupus erythematosus, Hamman-Rich syndrome, "myocarditis," subacute bacterial endocarditis, or even acute rheumatic fever (Skanse, Berg, and Westfelt, 1959 ; Lekisch, 1957). Hyperglobulinaemia has been reported (Skanse et al., 1959 ; Evans, 1959 ; Frankenfeld, Waters, and Steiner, 1960 ; MacGregor and Cullen, 1959), but has not been emphasized as much as the haemodynamic and embolic aspects of the disease.

The object of this paper is to present four patients proven clinically (three of whom had successful operations), with special reference to clinical features suggesting a generalized infection or general systemic disease. Particular attention is paid to changes in the serum proteins and to the physical signs. The haemodynamic effects, angiographic studies, the pathology, and the results of successful surgical removal are described.

\section{Patients Studied and Methods OF INVESTIGATION}

There were four patients; one man aged 63 years, and three women aged 48, 47, and 23 years. Clinical studies, phonocardiography, and cardiac catheterization were performed in all four, and angiocardiography in three. Selective angiograms were obtained of the right and left sides of the heart in one patient and of the right side only in two. The erythrocyte sedimentation rate and serum proteins were studied

\footnotetext{
*Advanced research fellow of the American Heart Association. t Lecturer in thoracic surgery, Ein Shams University, Cairo, U.A.R.

$\ddagger$ Nuffield Foundation research fellow in cardiac pathology.
}

repeatedly before and after operation in the three patients who came to surgery.

Patient 1.-A. G., a Lithuanian woman, aged 48 , was a poor historian, but denied rheumatic fever or chorea. In 1957 she was found to have atrial fibrillation, and following this she complained of general malaise, abdominal pain. dyspnoea on effort, generalized limb pains, and night sweats. In 1958 she developed thyrotoxicosis which resolved on medical treatment. The atrial fibrillation then reverted to sinus rhythm, but subsequently relapsed in 1959. At this time a murmur suggestive of mitral valve disease was heard, and later she developed substernal pain resembling angina of effort.

First Hospital Admission.-She was admitted to Hammersmith Hospital in October, 1959, for investigation. On examination she was a sallow, ill-looking woman. Gross clubbing of the fingers was noted: it had not been present four months previously. The pulse was $100 /$ minute, irregular from atrial fibrillation, and the blood pressure was about $110 / 75 \mathrm{~mm}$. Hg. The apical first heart sound was accentuated, and there was a short grade 2 mitral diastolic murmur and an early soft opening snap. The second heart sound was normal. There was no splenomegaly or lymphadenopathy.

Serum Proteins.-These were abnormal. the albumin level being $2.5 \mathrm{~g} . \%$ and the globulin $5.3 \mathrm{~g} . \%$ (Fig. 1). The haemoglobin was 12 g.\%. The white blood cell count was $6,000 / \mathrm{c} . \mathrm{mm}$. Blood cultures were repeatedly negative. The erythrocyte sedimenta. tion rate was $83 \mathrm{~mm}$./hour (Westergren).

Electrocardiography.-An electrocardiogram was normal before the development of atrial fibrillation (Fig. 2).

Radiography.-A chest radiograph showed enlargement of the right ventricle and left atrium, but no evidence of pulmonary vascular disorder, heart failure, or mitral valve calcification.

Progress.-The patient remained febrile and ill, and a diagnosis of subacute infective endocarditis of the mitral valve was made. However, she made no response to treatment with full doses of penicillin 


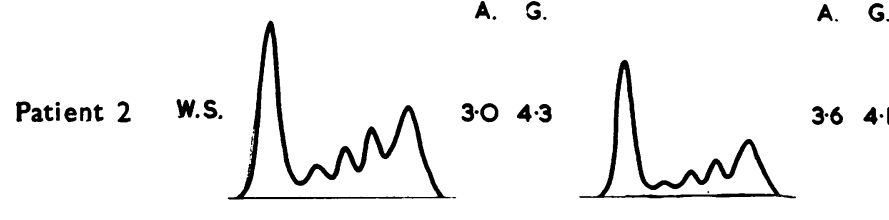
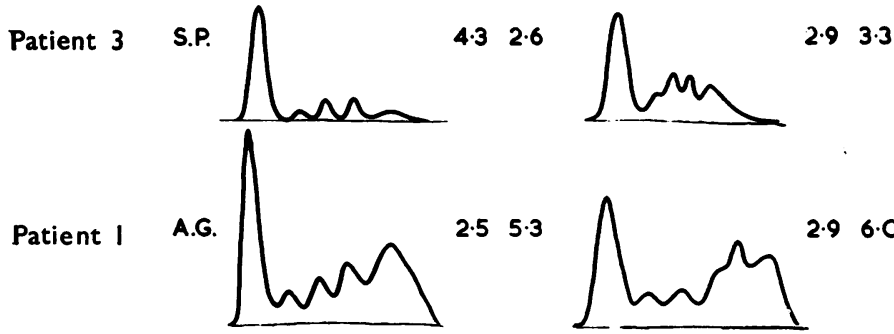

$5 \cdot 3$

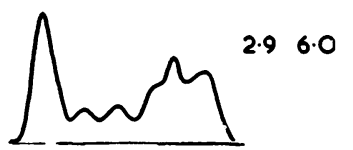

Patient 4

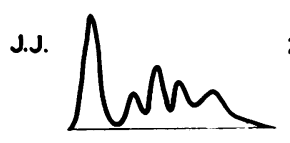

$2 \cdot 23 \cdot 6$

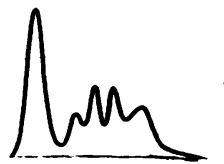

$2.6 \quad 3.8$
Fig. 1.-Two random estimations of serum proteins in each of the four patients. The studies were made before operation in Patients 2, 3, and 4. In each case the serum globulins, usually the gamma fractions, are raised, and the variability of the electrophoretic pattern in the same patient is apparent. $\mathbf{A}=$ albumin (g. \%); $\mathbf{G}=$ globulin (g. \%).

FIG. 2.-Eleztrocardiograms from the four patients. Patient 1 his a normal ventricular balance, but Patients 2 and 3 show grade 2, and Patient 4 shows grade 3 , right ventricular hypertrophy. $T$ wave inversion in $V_{5}$ and $V_{6}$ is notable in Patient 3 and is attributable to the effects of digitalis and right ventricular hypertrophy.

Fig. 1

$\begin{array}{llllllll}I & \text { II } & \text { III } & \text { VR } & \text { V4R } & \text { VI } & \text { V5 } & \text { V7 }\end{array}$

Patient I

A.G

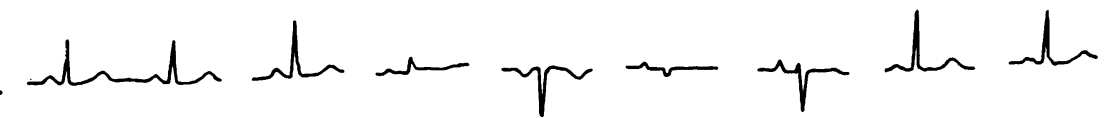

Patient 2

W.S.

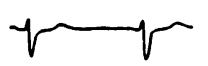<smiles>CCCCCCCCCCCCCCCC</smiles>

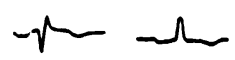

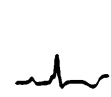<smiles>CCC(C)C(C)C</smiles>

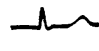

Patient 3

S.P.<smiles>CC(C)(C)CC(C)(C)C</smiles><smiles>CCCCCC(C)CCCC</smiles><smiles>CCC(C)CCC1(C)C(C)C1CC</smiles><smiles>CCCCCCCCCCCC</smiles><smiles>CCC(C)C(C)C</smiles><smiles>CCCCC</smiles>

Patient 4 J.J.

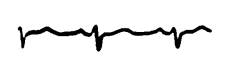<smiles>CCCC(C)(C)C</smiles><smiles>CCC(C)CC</smiles>

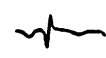

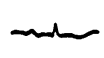<smiles>CCCCCCC</smiles><smiles>CCCCCCCC(C)(C)C(C)(C)CC</smiles>

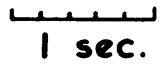


and streptomycin for six weeks. Other conditions were considered, and the possibility of left atrial myxoma was suggested by Dr. C. C. Booth. After extensive investigation no cause was found for her illness, and she was discharged for observation in the out-patient department at her own request in January, 1950. In April, 1960, she developed severe dyspnoea, cough, and rusty sputum, with slight swelling of the ankles. Substernal tightness was associated with dyspnoea.

Second Hospital Admission.--She was readmitted to hospital in May, 1960 . On examination she still looked ill and was febrile $\left(97.5^{\circ}\right.$ to $99.5^{\circ}$ F.). Atrial fibrillation was still present, and the jugular venous pressure was now $3 \mathrm{~cm}$. above the sternal angle. Pulmonary valve closure was greatly increased in intensity and was early in timing. A grade 2 pulmonary ejection murmur was heard and there was now a grade 3 systolic murmur at the apex, but the mid-diastolic murmur was softer and longer than previously. There was dullness at the base of the right lung, but the liver and spleen were not enlarged and there was no oedema. The gross clubbing of the fingers persisted.

Serum Proteins. - These remained abnormal, albumin levels ranging from 2.3 to $3.3 \mathrm{~g} . \%$ and globulin from 4.4 to 4.6 g.\% (Fig. 1). The haemoglobin was 10 g. $\%$ and the white blood cell count 7,000/c.mm. The erythrocyte sedimentation rate was $16 \mathrm{~mm}$./hour (Westergren).

Radiography.-A chest radiograph showed enlargement of the right ventricle, pulmonary artery, and left atrium, with signs of pulmonary arterial and venous hypertension. Small bilateral pleural effusions were initially present but cleared with treatment.

Cardiac Catheterization.-This was twice postponed or abandoned owing to threatened pulmonary oedema. On the third occasion the pulmonary artery pressure was 85/23 (mean 43) $\mathrm{mm}$. $\mathrm{Hg}$, but a pulmonary venous "wedge pressure" was not obtained (Table I).

\section{TABLE I}

RESULTS OF RIGHT HEART CATHETERIZATION IN LEFT ATRIAL MYXOMA

\begin{tabular}{|c|c|c|c|c|c|}
\hline & \multirow{2}{*}{ Patient 1} & \multirow{2}{*}{ Patient 2} & \multirow{2}{*}{$\begin{array}{c}\text { Patient } \\
3 *\end{array}$} & \multicolumn{2}{|c|}{ Patient 4} \\
\hline & & & & $(1) \dagger$ & (2) \\
\hline $\begin{array}{l}\text { Arterial } \mathrm{O}_{2} \\
(\%) \\
\text { Cardiac } \\
\text { nutput }\end{array}$ & 92 & 89 & - & 87 & - \\
\hline $\begin{array}{l}\text { (1. min.) } \\
\text { Right }\end{array}$ & - & $3 \cdot 0$ & 一 & $4 \cdot 6$ & - \\
\hline $\begin{array}{l}\text { ventricle } \\
\text { (mm. Hg) } \\
\text { Pulmonary }\end{array}$ & 757 & 8010 & 10020 & - & 897 \\
\hline $\begin{array}{l}\text { artery } \\
\text { (mm. Hg) } \\
\text { Pulmonary }\end{array}$ & $8523(43)_{+}^{+}$ & $9030(47)$ & 7538 & $-(39)$ & $8935(50)$ \\
\hline "wedge", & $4015(28)$ & (20) & (35) & (19) & $32 / 22(25)$ \\
\hline
\end{tabular}

Angiocardiography. - A venous angiocardiogram showed a small filling defect of doubtful significance in the left atrium. The arteries of the right lung filled less well than those of the left; the pulmonary veins were not visualized on the right side and were thought to be occluded.

Progress.-On June 3, 1960, the patient developed an infarct in the right lung and appeared to be deteriorating. The diagnosis was now considered to rest between a left atrial myxoma and severe mitral insufficiency following bacterial endocarditis. We decided to explore the left atrium, but the patient died before this could be done

Necropsy.-The heart, which weighed 420 g., contained in the left atrium a pedunculated myxoma which arose from the wall of the atrial septum a few millimetres from the posterior rim of the fossa ovalis, below the entrance of the pulmonary veins and slightly above the coronary sinus. It was firmly attached by a narrow pedicle, $8 \mathrm{~mm}$. in diameter, from which it expanded into a lobulated mass of greyishpink, gelatinous material $4 \mathrm{~cm}$. in its widest diameter. It hung down through the mitral valve ring, and the free end of the mass, which lay mainly in the confines of the mitral valve, had become converted into a twisted, pale, cheesy material in which there were fine flecks of calcium. The atrial surfaces of the mitral valve cusps in contact with this material had become abraded, and two of the chordae to the anterior cusp were severed. The valve ring was slightly dilated, but the valve was otherwise normal. The left atrium and right ventricle were both dilated and hypertrophied. The left ventricle was moderately dilated, but the wall was of normal thickness (Fig. $3 \mathrm{a}$ and $\mathrm{b}$ ).

PATIENT 2.-W.S., a man aged 63 years, had been well (with no history of rheumatic fever or previous cardiovascular disease), until he developed rapidly increasing exertional and paroxysmal nocturnal dyspnoea 28 months before admission to Hammersmith Hospital in September, 1960. Two years earlier he had been in sinus rhythm with an apical presystolic thrill, accentuated first heart sound, and increase in intensity of pulmonary closure. A pansystolic murmur was heard at the apex, and there was a diastolic rumbling murmur with presystolic accentuation. No opening snap was heard.

In April, 1960, the patient had experienced five episodes of vertigo and blurring of vision, followed a few seconds later by loss of consciousness for up to 10 minutes, usually associated with urinary incontinence. None of these episodes was observed by a doctor, but they were apparently related to changes in posture. There were no residual neurological symptoms or signs. During the two years of illness preceding his admission, he had lost $14 \mathrm{lb}$. in weight.

Examination on admission to Hammersmith Hospital revealed a pale, dyspnoeic, elderly man with slight peripheral cyanosis, but no definite clubbing of the fingers or toes. The pulse was regular at $100 /$ minute, the blood pressure was $95 / 70 \mathrm{~mm}$. $\mathrm{Hg}$. 


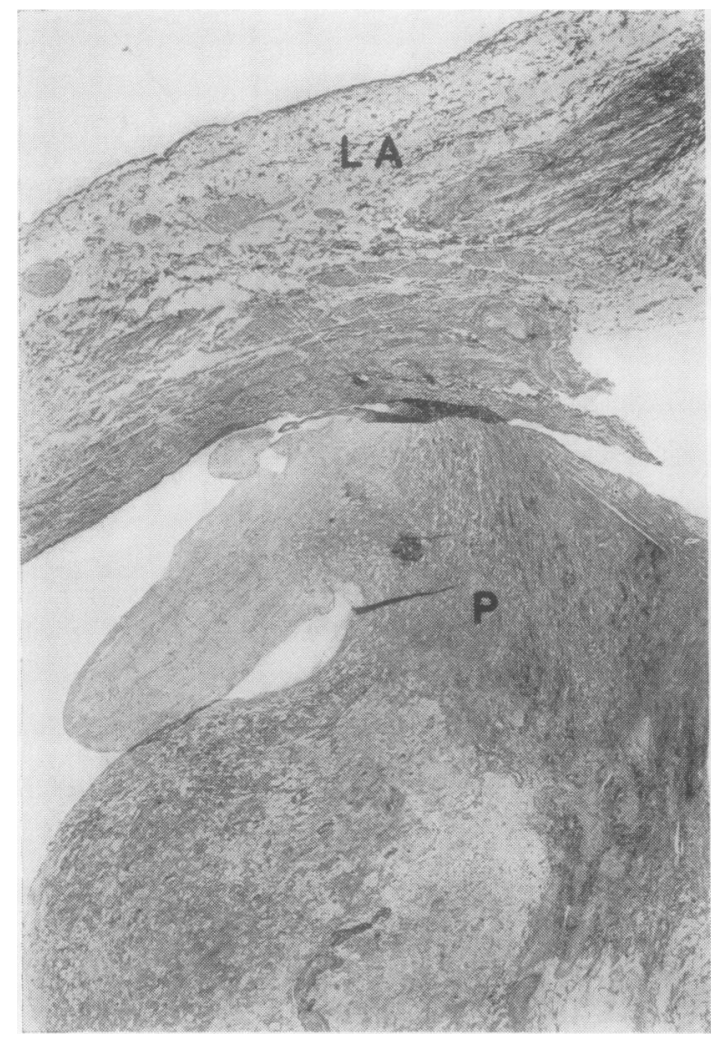

FIG. $3 \mathrm{a}$

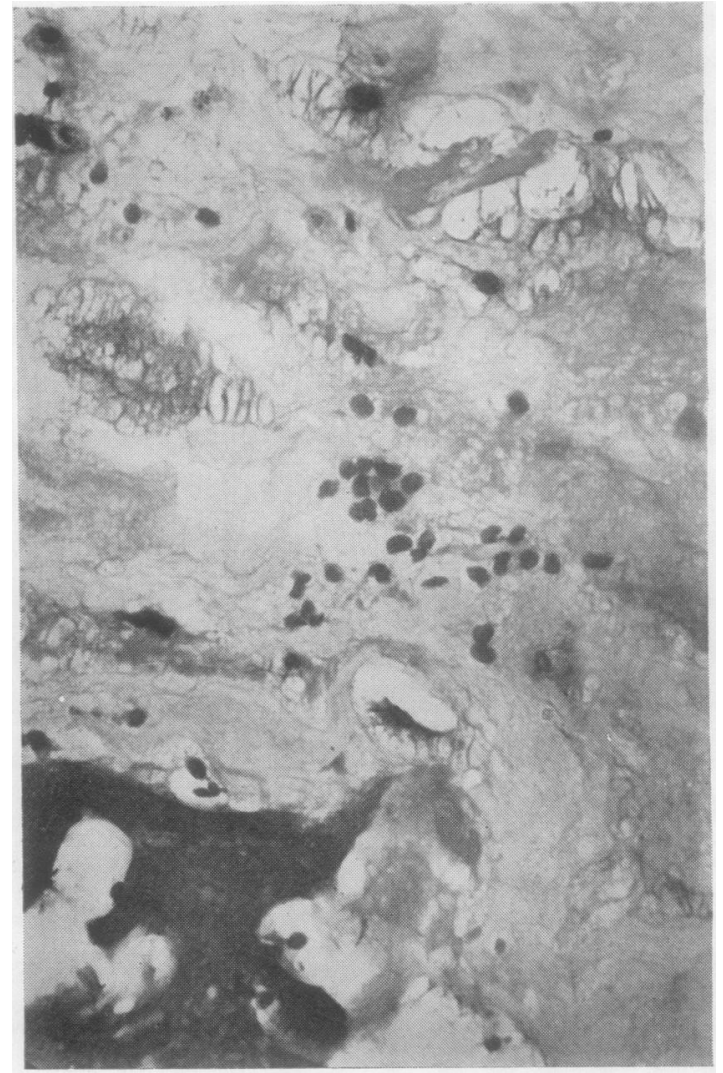

FIG. $3 b$

FIG. 3.-Patient 1: (a) Photomicrograph of the myxoma showing the attachment of the pedicle (P) to the left atrial wall (LA), H. and E. $\times 8 \cdot 4$. (b) High-power view of the myxoma, showing the characteristic cell with plump nucleus and processes extending irregularly into the myxoid stroma in which there is a scattering of red blood cells, H. and E. 370 .

and he was febrile $\left(97^{\circ}\right.$ to $100^{\circ}$ F.). The jugular venous pressure was raised to $10 \mathrm{~cm}$. above the sternal angle with a prominent "a" wave. There were crepitations at both lung bases. The cardiac impulse was not localized, but there was a right ventricular heave. At the apex there was a presystolic thrill and a full-length diastolic murmur with presystolic accentuation; the first sound was accentuated and followed by a grade 1 pansystolic murmur. No opening snap was heard, but the pulmonary component of the second sound was accentuated. The liver edge was palpable $5 \mathrm{~cm}$. below the right costal margin, but the spleen was not felt. The peripheral arterial pulses were all present but of small volume, and there was no oedema.

Serum Proteins.-These were repeatedly abnormal during the course of the illness, and were recorded as follows: albumin $3.3,3.0$, and $3.6 \mathrm{~g} . \%$; globulin 4.4. 4.3. and 4.1 g. \% (Fig. 1). The haemoglobin was $11.5 \mathrm{~g} . \%$, white blood cell count $7.000 / \mathrm{c} . \mathrm{mm}$., with a normal differential count. The red blood cells were hypochromic. The blood urea was $49 \mathrm{mg}$."\% and the erythrocyte sedimentation rate was $10 \mathrm{~mm}$./hour (Westergren).

Electrocardiography. - An electrocardiogram showed sinus rhythm and grade 2 right ventricular hypertrophy (Fig. 2).

Radiography. - A chest radiograph showed enlargement of both ventricles and of the pulmonary artery, but the left atrium was only slightly enlarged. There were signs of pulmonary arterial and venous hypertension.

Progress.-On the eighth day after admission the patient developed fever to $101^{\circ} \mathrm{F}$., which persisted for three days. He was found to have microscopic haematuria and the blood urea rose to $60 \mathrm{mg} . \%$. but blood cultures were repeatedly sterile. The sedimentation rate was now $32 \mathrm{~mm}$./hour. On the eleventh day after admission penicillin, streptomycin, and probenecid were started as treatment for subacute bacterial endocarditis and continued for six weeks. 
It was considered that the mitral valve was infected. The blood urea reached a maximum value of $77 \mathrm{mg} . \%$, but had fallen to $47 \mathrm{mg}$. \% three weeks after admission. The sedimentation rate rose to $34 \mathrm{~mm}$./hour, but fell after one month's treatment to $10 \mathrm{~mm}$./hour. Haematuria did not persist after a fortnight in hospital.

Three weeks after his admission the cardiac murmurs were found to have changed, and the apical pansystolic murmur was now of grade 3 intensity and was transmitted to the axilla; the mid-diastolic murmur was still present, but was softer and shorter, and the presystolic accentuation and thrill had disappeared. The erythrocyte sedimentation rate was $60 \mathrm{~mm}$./ hour on the sixty-third day after admission, and the patient did not seem to have benefited from the treatment for bacterial endocarditis.

In view of the changing murmurs, failure to respond satisfactorily to treatment, persistently high sedimentation rate, abnormal proteins, and fever in the absence of positive blood cultures, the possibility of a left atrial myxoma was considered.

Cardiac Catheterization.-Catheterization of the right heart was performed two months after admission. The cardiac output was $3 \mathrm{l}$./minute, pulmonary artery pressure $90 / 30 \mathrm{~mm}$. $\mathrm{Hg}$, and mean pulmonary artery "wedge pressure" $20 \mathrm{~mm}$. $\mathbf{H g}$ with prominent " $v$ " waves, suggesting mitral insufficiency (Table I).
Angiocardiography revealed a filling defect in the left atrium of doubtful significance. This filling defect was lobulated and of a type not previously seen in our angiographic studies in mitral valve disease. It resembled that found in our first patient, and was similar to the appearances illustrated by Goldberg. Glenn, Dotter, and Steinberg (1952) and by Steinberg. Dotter, and Glenn (1953) in cases of left atrial myxoma. A retrograde left ventricular angiogram was performed which showed marked reflux of contrast medium into the left atrium, indicating severe mitral incompetence; it also confirmed the lobulated filling defect in the atrium produced by the myxoma. On several films the tumour appeared to be mobile and to prolapse from the left atrium into the left ventricle and vice versa (Fig. $4 \mathrm{a}$ and $\mathrm{b}$ ).

Operation (Mr. L. L. Bromley and H. H. B.).-The right atrium was exposed through a right anterolateral thoracotomy in the fourth intercostal space. Routine cannulations of the left common femoral artery and the superior and inferior venae cavae were performed, care being taken to site the caval cannulae well posteriorly. Normothermic cardio-pulmonary bypass was instituted.

The tumour was approached through an incision placed anteriorly in the right atrium. The inter-atrial septum was incised above the fossa ovalis and the incision was gradually enlarged as the soft gelatinous
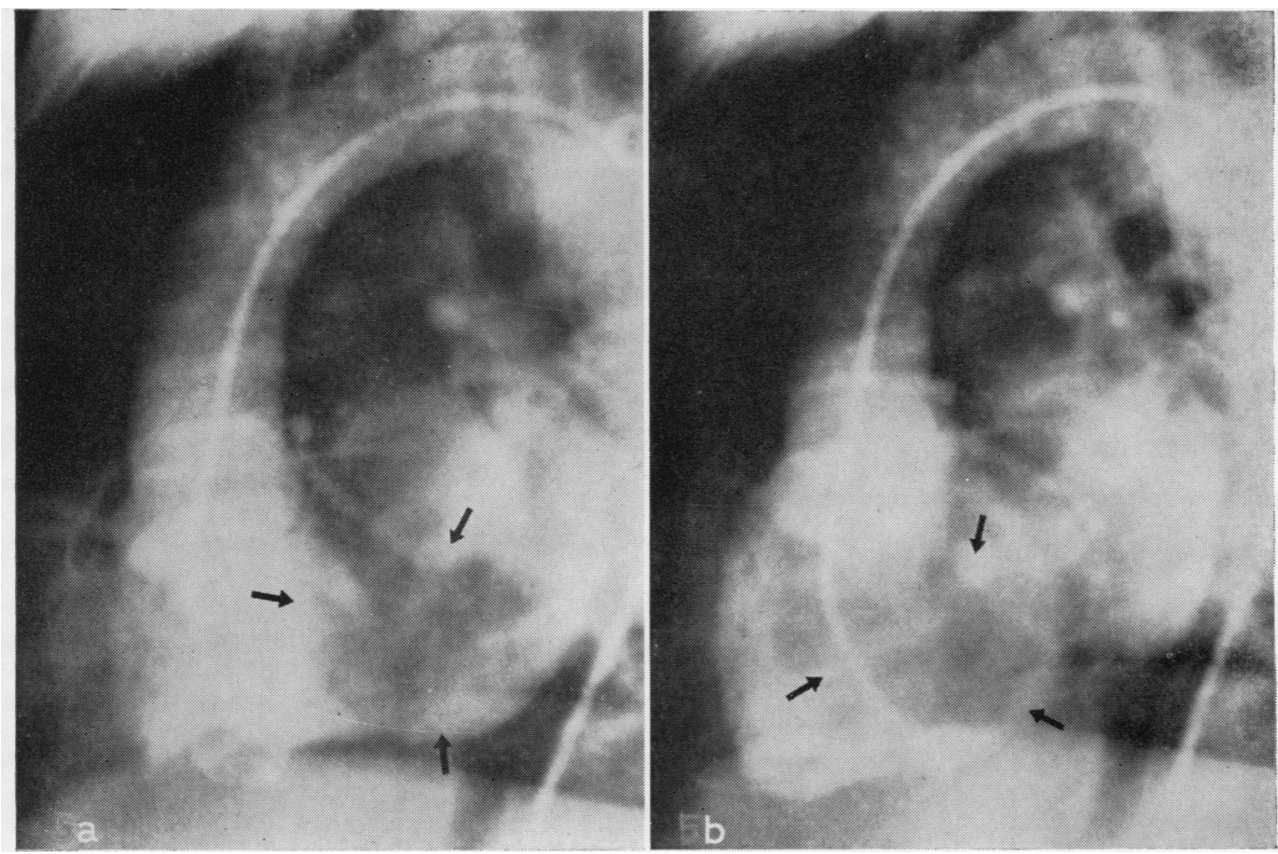

FIG. 4.-Patient 2. Retrograde left ventricular angiogram (lateral projection): (a) contrast medium spreading back into the left atrium from the left ventricle, indicating mitral incompetence; there is a lobulated filling defect in the $1 \geq \mathrm{ft}$ atrium due to the myxoma (arrowed); (b) half a second later the filling defect can be seen in the left ventricle, due to prolapse of the myxoma through the mitral valve. 
tumour presented. There was a small $(1 \mathrm{~cm}$.) pedicle situated near the superior margin of the fossa ovalis. The pedicle was excised with the complete thickness of the septum. The tumour was gradually delivered, disimpacting that part which had prolapsed through the normal mitral valve. The impression caused by the mitral valve ring was clearly seen as a constriction. The aorta was clamped to prevent the possibility of tumour embolus. The main bulk of the tumour was delivered intact, but some fragments were detached. These fragments were removed by sucking; the left atrium and left ventricle were washed with normal saline and sucked dry several times, all products of suction being discarded.

The left ventricle and left atrium were allowed to refill with blood and the incision in the atrial septum was repaired.

The total period of aortic occlusion was six minutes, and of cardio-pulmonary bypass 21 minutes. Pressures were recorded before and after removal of the tumour and are set out in Table II.

\section{TABLE II}

VASCULAR PRESSURES BEFORE AND AFTER REMOVAL, OF LEFT ATRIAL MYXOMA

\begin{tabular}{|c|c|c|c|c|c|c|}
\hline \multirow[b]{2}{*}{ Patient } & \multicolumn{2}{|c|}{$\begin{array}{c}\text { Pulmonary Artery } \\
(\mathrm{mm} . \mathrm{Hg})\end{array}$} & \multicolumn{2}{|c|}{$\begin{array}{l}\text { Left Atrium } \\
(\mathrm{mm} . \mathrm{Hg})\end{array}$} & \multicolumn{2}{|c|}{$\begin{array}{l}\text { Systemic Artery } \\
(\mathrm{mm} . \mathrm{Hg})\end{array}$} \\
\hline & Before & After & Before & After & Before & After \\
\hline $\begin{array}{l}2 \\
3 \\
4\end{array}$ & $\begin{array}{l}60 / 20(45) \\
55 / 30(42) \\
42 / 35(22)\end{array}$ & $\begin{array}{l}55 / 30(37) \\
60 / 30(38) \\
38 / 18(25)\end{array}$ & $\begin{array}{l}40 / 20 \\
60 / 18 \\
30 / 12\end{array}$ & $\begin{array}{l:l}18 & 10 \\
20 & 10 \\
20 & 10\end{array}$ & $\begin{array}{c}70: 40 \\
100: 60(78) \\
82 / 56(68)\end{array}$ & $\begin{array}{c}90- \\
100 / 60(78) \\
115 / 62(80)\end{array}$ \\
\hline
\end{tabular}

Mean pressures are shown in parentheses.

Pathology.-The tissue removed at operation weighed $54 \mathrm{~g}$. and consisted of several fragments and a larger mass, $7 \times 4 \times 3 \mathrm{~cm}$. in its widest diameters, which comprised the bulk of the tumour. The smaller fragments were mainly soft and gelatinous. At one edge of the main mass was a narrower, somewhat fibrotic pedicle, $1 \mathrm{~cm}$. in diameter, and $3 \mathrm{~cm}$. away from this edge of the myxoma there was a slight constriction made by the mitral valve ring. The bulbous free end was presumably that portion which had been situated mainly in the left ventricular cavity (Fig. 5).

Post-operative Course.-This was uneventful apart from hypotension during the first $\mathbf{4 8}$ hours. The apical systolic murmur became much reduced in intensity, but signs of pulmonary hypertension persisted. Subsequently, the patient improved greatly, the dyspnoea disappeared, he put on weight, and his fever resolved completely. The serum proteins became normal (Fig. 6).

Patient 3.-S. P., a woman aged 23 years, first noted dyspnoea on climbing stairs and a persistent cough following a bout of bronchitis in 1958. In November. 1960 , she was referred by Drs. Davies and Barritt, of Bristol, who suspected the presence of myxoma of the left atrium. She had previously been well and had no history of rheumatic fever.

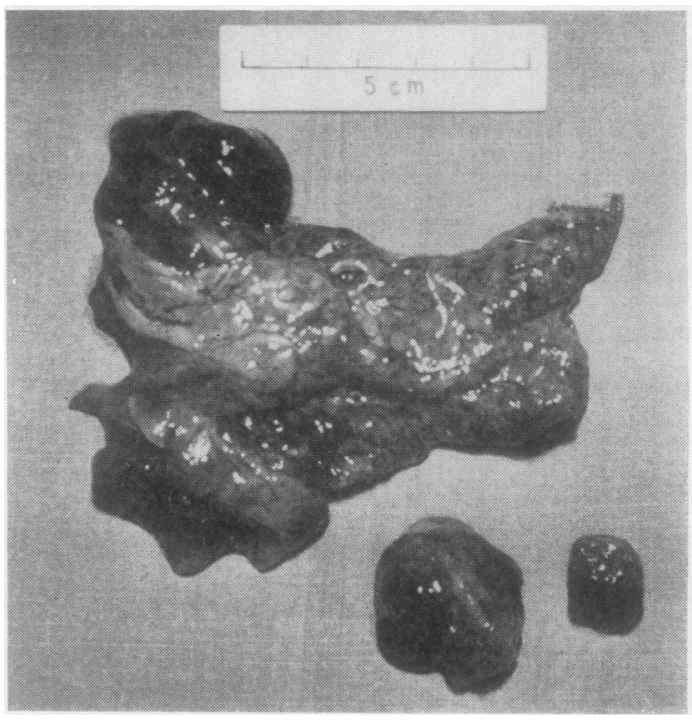

Fig. 5.-Patient 2. Myxoma removed at operation

In February, 1959, she was found to have a lowgrade fever, an apical diastolic murmur, and an erythrocyte sedimentation rate of $36 \mathrm{~mm}$./hour. A diagnosis of active rheumatic carditis was made, and she was sent home to rest for two months. Between August, 1959, and February, 1960, the erythrocyte sedimentation rate varied from 14 to $25 \mathrm{~mm}$./hour. In June, 1960, she was admitted to the Bristol Royal Hospital because of exertional dyspnoea, fatigue, cough, fever, tachycardia, and oedema of the ankles. On examination she was thin and ill with evidence of pulmonary hypertension. Systolic and diastolic murmurs and a third heart sound were heard at the cardiac apex. Catheterization of the right heart revealed a pulmonary artery pressure of $75 / 30 \mathrm{~mm}$. $\mathrm{Hg}$ and a pulmonary artery "wedge pressure" of $35 \mathrm{~mm}$. $\mathrm{Hg}$ (Table I). During catheterization the patient developed pulmonary oedema and hypotension and was gravely ill for several days. She made a slow and partial recovery, but remained in hospital until September, 1960. During this time the low-grade fever and tachycardia persisted, but the serum globulins were not raised.

She was transferred to Hammersmith Hospital in November, 1960, complaining of severe dyspnoea and orthopnoea; she had lost $30 \mathrm{lb}$. in weight during the two years of her illness.

On examination she was afebrile, but appeared pale. wasted, ill, and dyspnoeic. Pale, cold extremities and a small pulse volume indicated a low cardiac output. The pulse was regular at 120 /minute and the blood pressure was $95 / 70 \mathrm{~mm}$. Hg. Crepitations were heard at both lung bases. Jugular venous " $a$ " and " $v$ " waves rose to $5 \mathrm{~cm}$. above the sternal angle. There was a right ventricular heave but the left ventricle 


\section{Before Operation}
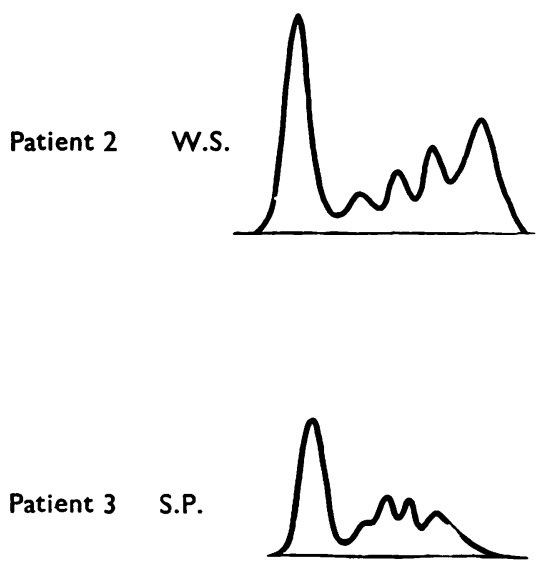

A. $2 \cdot 9$

G. $3 \cdot 3$

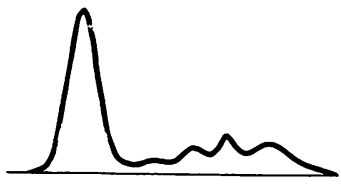

A. $4 \cdot 6$

G. $2 \cdot 9$
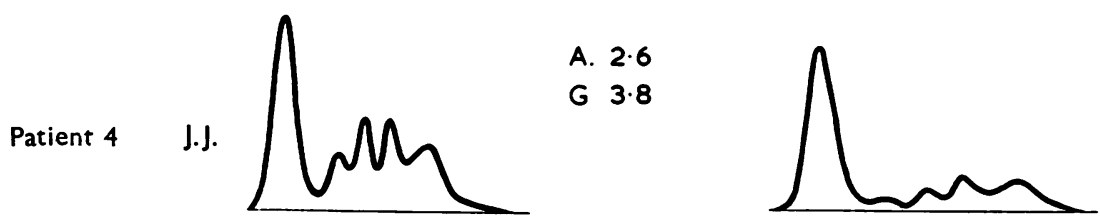

A. $4 \cdot 3$

G. $2 \cdot 6$

Fig. 6.-Serum proteins before and after operation. In all three patients the abnormal albumin $/$ globulin ratio became norma!. $A=$ albumin (g. \%); G=globulin (g. \%).

was not enlarged clinically. The first heart sound at the apex was accentuated, and there was a grade 3 apical pansystolic murmur with a loud third heart sound which was heard maximally over the right ventricle and more softly towards the axilla. No apical diastolic murmur was heard. In the pulmonary area a grade 1 ejection systolic murmur with ejection click was followed by a narrowly split second with accentuation of the pulmonary component. The liver and spleen were not felt.

Serum Proteins.-These became abnormal. On the third day after admission the albumin was $4.3 \mathrm{~g} . \%$ and the globulin $2.6 \mathrm{~g} . \%$, but on the twenty-ninth day after admission the albumin was 3.2 g. $\%$ and the globulin 3.3 g. \% (Fig. 1). The haemoglobin was $12.3 \mathrm{~g} . \%$, white blood cell count $8,000 /$ c.mm., with a normal differential count. The urine was normal. Blood cultures were repeatedly negative.

Electrocardiography. -- An electrocardiogram showed sinus rhythm with slight atrial and grade 2 right ventricular hypertrophy (Fig. 2).

Radiography.-A chest radiograph showed enlargement of the right ventricle, pulmonary artery, and both atria. Horizontal costophrenic lines, indicating pulmonary venous hypertension, were present in both lower lung fields, and there was an effusion at the right base (Fig. 7 a-d).

Isotope studies of regional pulmonary blood flow by Dr. C. T. Dollery showed reduced perfusion to the lower portions of the lungs, typical of left atrial and mitral obstruction.

Progress. - The dyspnoea gradually increased despite treatment with rest, digitalis, and diuretics. There was pleuritic pain at the base of the right lung. suggesting pulmonary infarction. The apical systolic murmur was noted to vary in intensity from day to day, and slight clubbing of the fingers, absent on admission, was noted a month after the patient had been in hospital.

Her critical illness and the history of pulmonary oedema during previous cardiac catheterization contraindicated angiocardiography to confirm the diagnosis of left atrial myxoma, and because the clinical diagnosis seemed almost certain, operation was carried out 37 days after admission to hospital.

Operation (H. H. B. and Mr. L. L. Bromley).-The operation was performed in a similar manner to that on Patient 2 under normothermic bypass. On opening the chest the right lung was found to be stiff and the pulmonary lymphatics distended. Both atria were enlarged and tense. A myxoma was found to. 
extend from a stalk attached near the fossa ovalis through a normal mitral valve. The details of the technique were almost identical with those in the previous patient.

The period of aortic clamping was seven minutes and the duration of bypass 28 minutes.

Diagnostic pressures were recorded before and after removal of the tumour (Table II).
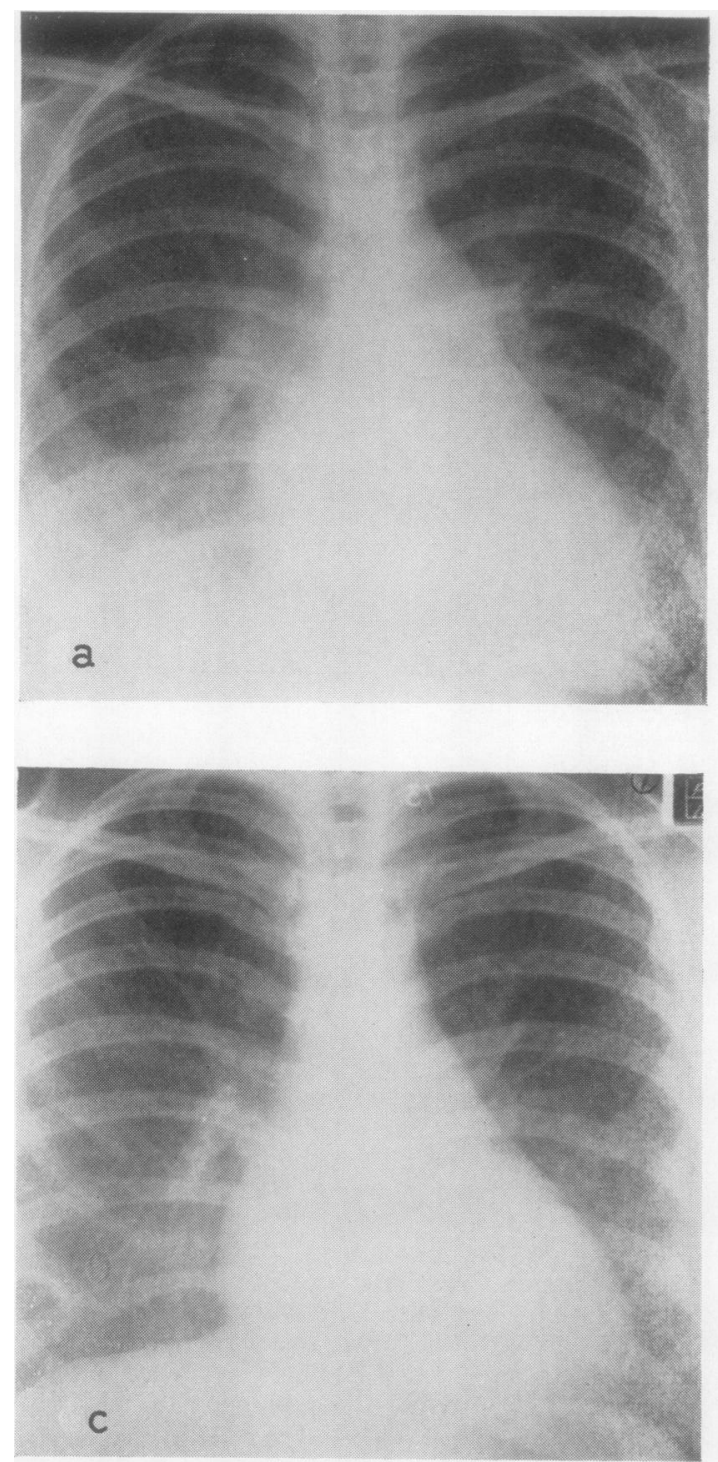

Pathology.-The total weight of the tissue removed was $48 \mathrm{~g}$. In addition to several small gelatinous fragments, there was a similar large tumour mass with a narrow pedicle, $7 \mathrm{~mm}$. in diameter. a smaller atrial portion being separated by a fairly sharp constriction from a larger, irregularly shaped ventricular portion measuring $4 \times 3 \mathrm{~cm}$.

Post-operative Course.-This was unremarkable except for transient hypotension and bigeminal
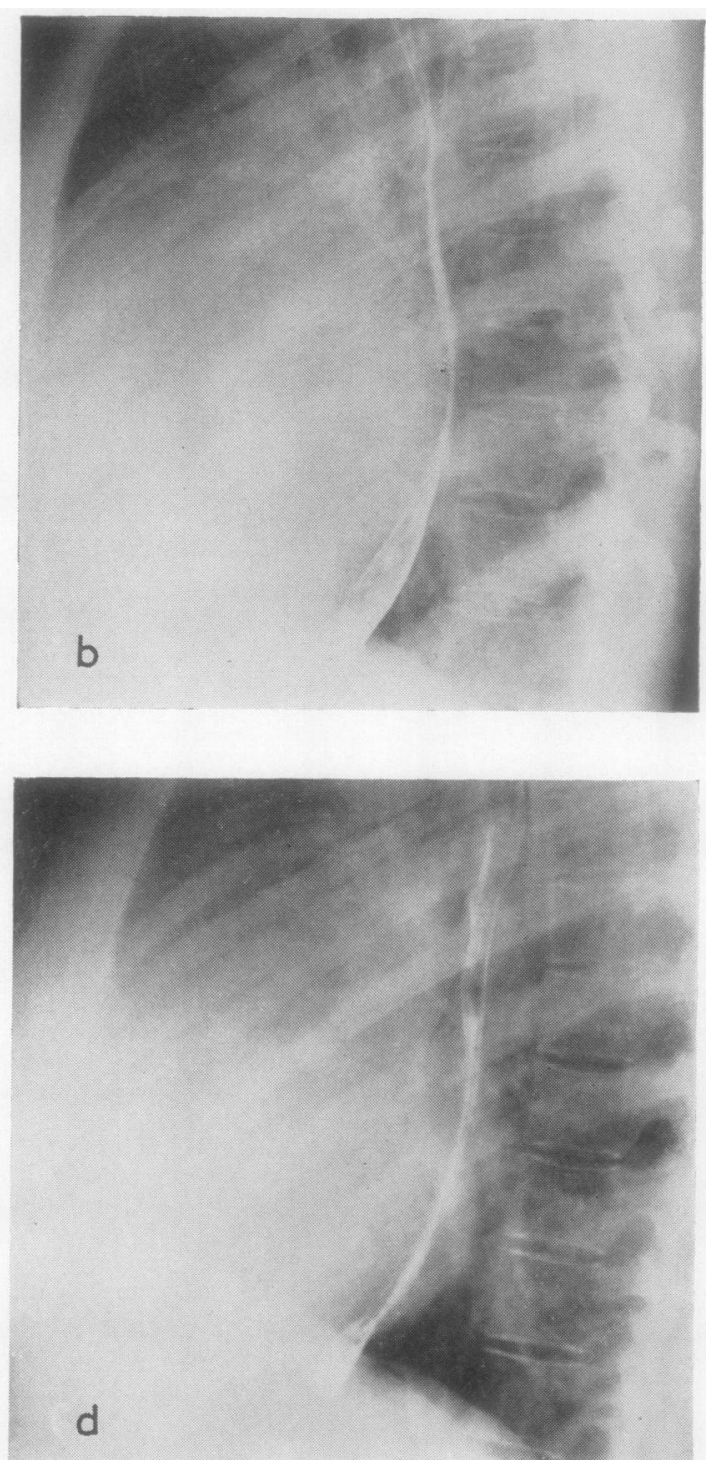

FIG. 7.-Patient 3. Chest radiographs before and after operation: (a) pre-operative postero-anterior film showing a right basal effusion, and enlargement of the main pulmonary arteries indicating pulmonary arterial hypertension; signs of venous hypertension are not well seen (see text); (b) pre-operative lateral film showing right ventricular and left atrial enlargement; (c) post-operative postero-anterior film showing reduction in size of the main pulmonary arteries and resolution of the right basal effusion; (d) post-operative lateral film showing reduction in size of the left atrium. 
rhythm. The apical systolic murmur and third sound disappeared. The patient subsequently made an uninterrupted recovery and gained $35 \mathrm{lb}$. in weight. The jugular venous pressure became normal and signs of pulmonary hypertension regressed. The effusion at the base of the right lung cleared (Fig. 7c). It was considered to have been due to obstruction of the right lower lobe pulmonary veins by thrombosis attributable to the low cardiac output and the severe pulmonary hypertension and vascular disorder. The serum proteins returned to normal (Fig. 6).

Patient 4.-J.J., a woman aged 47 , was healthy until nine months before her admission to King's College Hospital on January 20, 1961. During that time she developed fatigue, dyspnoea, lethargy, and general malaise, with sweating at night. On several occasions syncopal attacks followed sudden turning in bed. She had lost $28 \mathrm{lb}$. in weight. There was no history of rheumatic fever, and when she was examined in 1954 no abnormality had been found.

A left atrial myxoma was suspected by Dr. Bruce Pearson and Mr. W. P. Cleland on the basis of the history and signs which were suggestive, but not typical, of mitral valve disease, heart failure of rapid onset, and syncopal attacks. Cardiac catheterization showed pulmonary venous and arterial hypertension (Table I). She was transferred to Hammersmith Hospital on February 20, 1961.

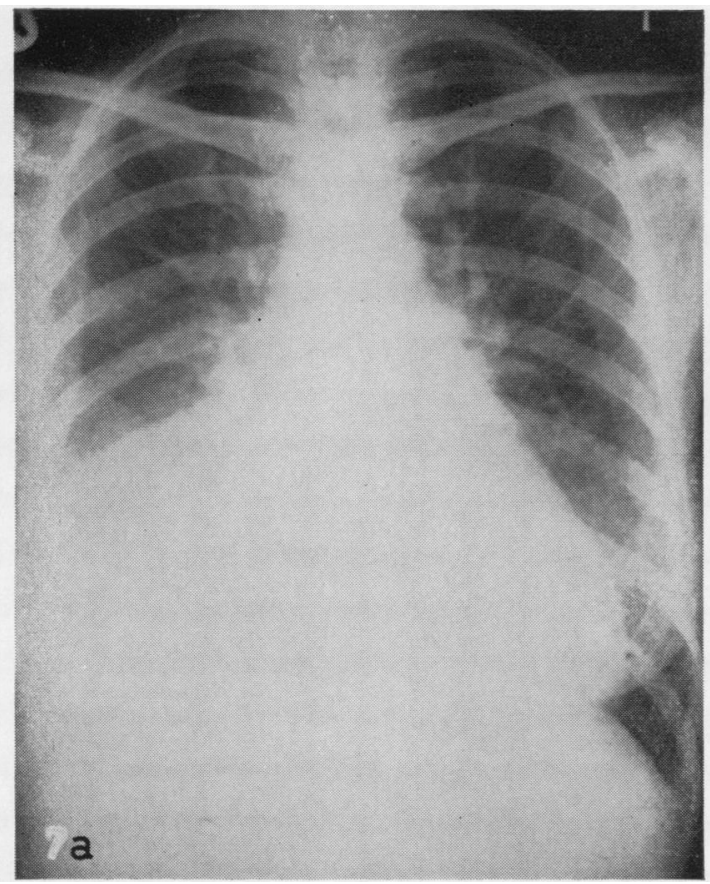

On examination she was an ill woman with orthopnoea, obvious loss of weight, pallor, and slight clubbing of the fingers. Arterial pulses were normal. but the jugular venous pressure was raised to $5 \mathrm{~cm}$. above the sternal angle with a prominent "a" wave. The blood pressure was $105 / 70 \mathrm{~mm}$. Hg. The cardiac impulse was right ventricular in type with a sternal heave. The first heart sound was accentuated and there was a short low-pitched early diastolic sound and short soft presystolic murmur at the apex. There was no opening snap. The murmurs and sounds did not change with posture. The pulmonary closure sound was accentuated and the split was narrow. There were crepitations at the lung bases, and the liver, but not the spleen, was enlarged.

Serum Proteins.-These were abnormal. the albumin leveis ranging from 2.2 to $2.6 \mathrm{~g}$. \% and the globulin from 3.6 to $3.8 \mathrm{~g}$.\% (Fig. 1). The haemoglobin was $10.5 \mathrm{~g} . \%$, the white blood cell count ranged from 6,000 to 12,000 per c.mm., and the erythrocyte sedimentation rate from 15 to $22 \mathrm{~mm}$./hour.

Electrocardiography. - An electrocardiogram showed grade 3 right ventricular hypertrophy and low voltage (Fig. 2).

Radiography.-A chest radiograph showed enlargement of the right ventricle, pulmonary arteries, left atrium, and possibly the left ventricle. There was marked pulmonary arterial and venous hypertension.

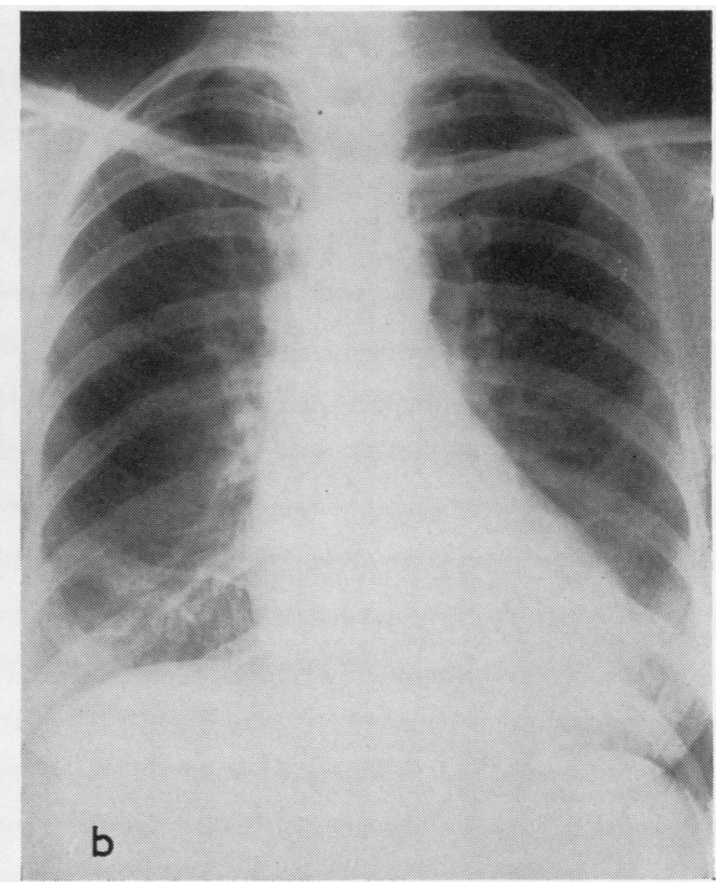

FIG. 8.-Patient 4. Pre- and post-operative postero-anterior cnest radiographs: (a) pre-operative, showing enlargement of the heart and the main pulmonary arteries and an effusion and consolidation at the right base; the upper lobe vessels are distended, but signs of venous hypertension are not well seen; (b) post-operative: the right base is now clear and the main pulmonary arteries are smaller. 
There was no evidence of calcification in the region of the mitral valve. Consolidation and an effusion at the right base were probably due to pulmonary infarction (Fig. 8).

Cardiac Catheterization and Selective Pulmonary Arteriography.-This demonstrated a pulmonary artery pressure of $89 / 35$ (mean 50 ) $\mathrm{mm}$. $\mathrm{Hg}$ and a wedge pressure of $32 / 22$ (mean 25$) \mathrm{mm}$. $\mathrm{Hg}$ (Table I). The main pulmonary arteries were greatly enlarged and the basal segmental branches tortuous and narrowed, especially on the right side. The left atrium was enlarged and a lobulated filling defect was seen within it. On several films the defect was seen to move from the left ventricles to the left atria, indicating its mobility through the mitral valve. The right lower lobe pulmonary vein failed to fill with contrast medium, indicating obstruction by thrombus or myxoma (Figs. $9 \mathrm{a}$ and $\mathrm{b}$ and $10 \mathrm{a}-\mathrm{e}$ ). The retention of contrast medium in the right lower lobe pulmonary arteries indicated obstruction to flow through that lung segment.

Operation (Mr. W. P. Cleland).-The chest was opened through a median sternotomy and operation carried out using normothermic cardio-pulmonary bypass. A soft lobulated myxoma was found attached to the region of the fossa ovalis (Fig. 11).

Details of the subsequent procedure were similar to those in the previous two patients.

The perfusion time was 41 minutes, and three periods of aortic clamping of two minutes, two minutes, and seven minutes were required.

Diagnostic pressures were recorded before and after operation, and showed a rise in systemic, a fall in left atrial, but little fall in pulmonary artery, pressures (Table II and Fig. 12).

Pathology.-The total weight of the myxoma removed was $37 \mathrm{~g}$. It was a discrete rounded mass $4 \times 3 \times 2 \mathrm{~cm}$. in its widest diameters, and lacked a constricting ring, suggesting that it had been mainly intra-atrial. The pedicle was small, $5 \mathrm{~mm}$. in diameter, and the mass mushroomed out from its point of attachment with a more rounded, lobular surface. The colour was pinkish yellow and noticeably paler than the previous examples. It differed also in that there was a discrete central area of calcification $1 \mathrm{~cm}$. in diameter.

Post-operative Course.-This was uneventful except for pulmonary infarction in the immediate postoperative period. Two months after the operation the patient had lost all her symptoms and had gained weight. The jugular venous pressure was normal, and a third heart sound, but no murmur, was heard at the apex. Pulmonary valve closure remained slightly accentuated, but the right basal shadow cleared. The serum proteins had become normal, the albumin being 4.3 g. $\%$ and globulin 2.6 g. \% (Fig. 6).

\section{Special Features of the Disease}

Symptoms.-Table III sets out the symptoms in the four patients described. Dyspnoea, orthopnoea, fatigue, and loss of weight were common to all. None had a history of rheumatic fever. The emphasis in the symptomatology was on pulmonary hypertension and a generalized toxic infective process more than on syncope or emboli. Syncope, however, occurred in two patients, but was related to posture in only one. In one patient (who also had a renal embolism) syncopal attacks may have been due to small cerebral emboli.

\section{TABLE III}

SYMPTOMS IN LEFT ATRIAL MYXOMA

\begin{tabular}{lcccc}
\multicolumn{1}{c}{ Symptoms } & \multicolumn{5}{c}{ Patient } \\
\cline { 2 - 5 } & -1 & 2 & 3 & 4 \\
\hline Dyspnoea & + & + & + & + \\
Orthopnoea & + & + & + & + \\
Paroxysmal nocturnal dyspncea & $?$ & + & + & 0 \\
Acute pulmonary oedema & + & 0 & + & 0 \\
Cough & + & 0 & $+\frac{1}{+}$ & + \\
Haemoptysis & + & 0 & 0 & + \\
Palpitation & $+($ A.F.) & + & 0 & 0 \\
Chest pain & + & 0 & + & + \\
Oedema & + & 0 & + & 0 \\
Fatigue & + & + & + & + \\
Weight loss (Ib.) & 51 & 14 & 30 & 28 \\
Syncope & 0 & Spon- & 0 & Exertion, \\
& & taneous & & posture
\end{tabular}
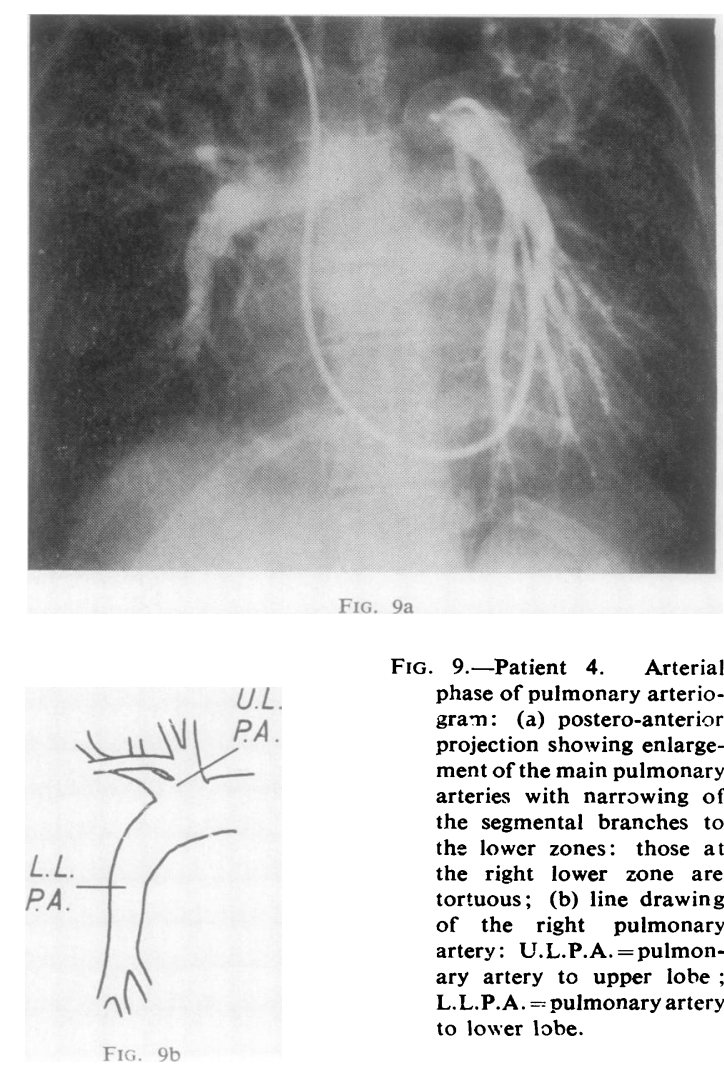

FIG. 9.-Patient 4. Arterial phase of pulmonary arteriogram: (a) postero-anterior projection showing enlargement of the main pulmonary arteries with narrowing of the segmental branches to the lower zones: those at the right lower zone are tortuous; (b) line drawing of the right pulmonary artery: U.L.P.A. = pulmonary artery to upper lobe ; L.L.P.A. = pulmonary artery to lower lobe. 

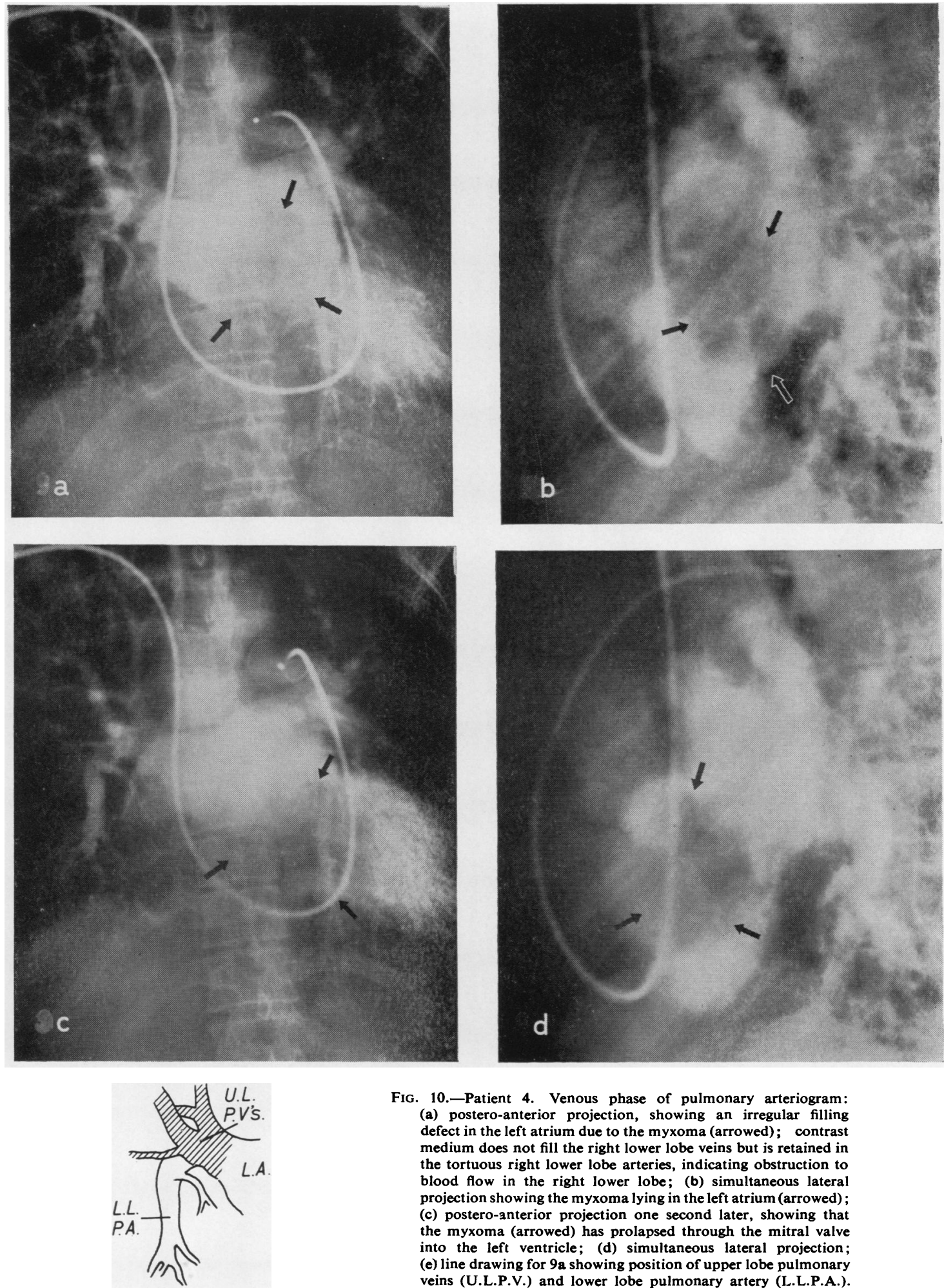

Fig. 10.-Patient 4. Venous phase of pulmonary arteriogram: (a) postero-anterior projection, showing an irregular filling defect in the left atrium due to the myxoma (arrowed); contrast medium does not fill the right lower lobe veins but is retained in the tortuous right lower lobe arteries, indicating obstruction to blood flow in the right lower lobe; (b) simultaneous lateral projection showing the myxoma lying in the left atrium (arrowed);

(c) postero-anterior projection one second later, showing that the myxoma (arrowed) has prolapsed through the mitral valve into the left ventricle; (d) simultaneous lateral projection; (e) line drawing for $9 \mathrm{a}$ showing position of upper lobe pulmonary veins (U.L.P.V.) and lower lobe pulmonary artery (L.L.P.A.) (LA $=$ left atrium.) 


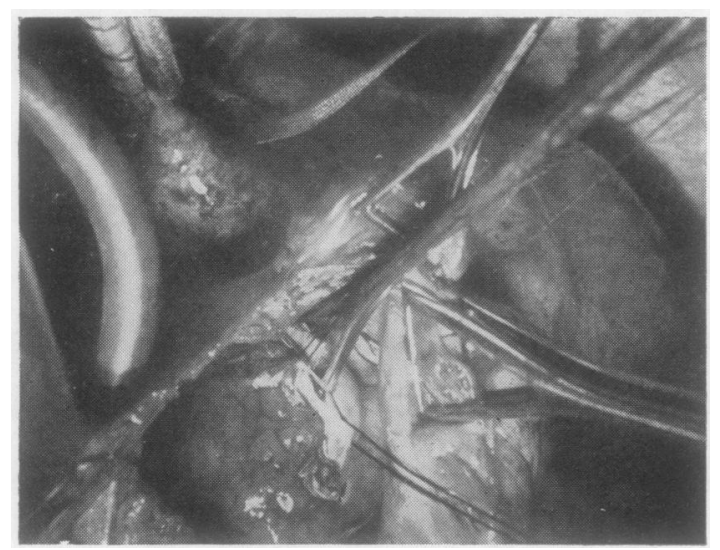

FIG. 11.-Patient 4. View of right atrium showing myxoma partly delivered through the atrial septum.
Clinical Signs (Table IV).--Fever was present in all patients and was usually low grade $\left(99^{\circ} \mathrm{F}\right.$.), but occasionally temperatures of up to $101^{\circ} \mathrm{F}$. were recorded. All the patients looked ill, haggard, and pale, and had obviously lost weight. Splenomegaly was never found, but the liver was enlarged in two patients. Clubbing of the fingers was found in three patients, and was gross in one.

As far as we are aware this has not previously been described. Judging by the slight degrees in three of our patients, it might easily have been missed in other reported cases, and it was not mentioned in MacGregor and Cullen's (1959) patient. The cause is quite unknown; our patients did not have arterial desaturation, pulmonary sepsis, or hepatic or gastrointestinal disease. It is possible that arterio-venous shunts occurred in the lungs as a response to the vascular obstruction, and we have very occasionally noticed clubbing

\section{Before}

B.A.

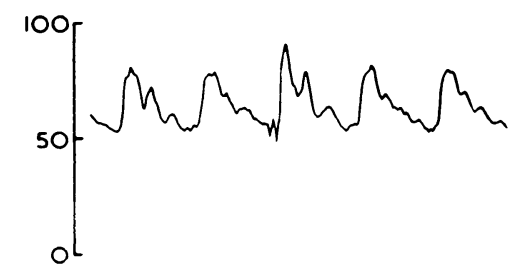

P.A.

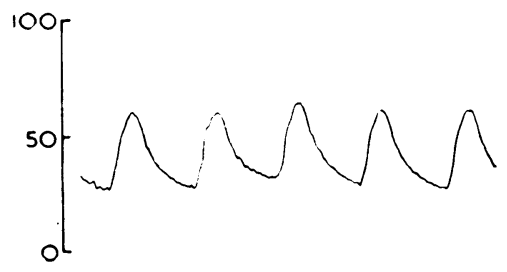

L.A.

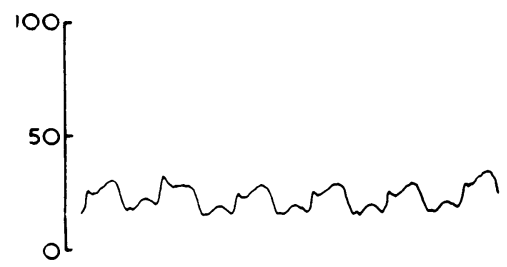

After
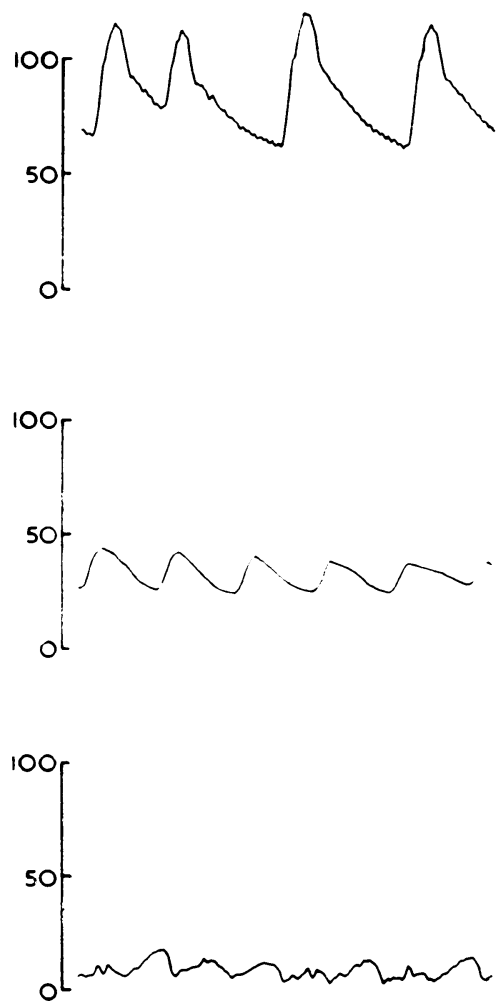

Fig. 12.--Patient 4. Systemic arterial (B.A.), pulmonary arterial (P.A.), and left atrial (L.A.) pressures immediately before and after removal of left atrial myxoma. The brachial artery pressure has risen, and the left atrial has fallen, indicating a decrease in pulmonary vascular resistance and an increase in cardiac output following removal of the obstruction (pressure in $\mathrm{mm}$. $\mathrm{Hg}$ ). 
TABLE IV

CLINICAL SIGNS IN LEFT ATRIAL MYXOMA

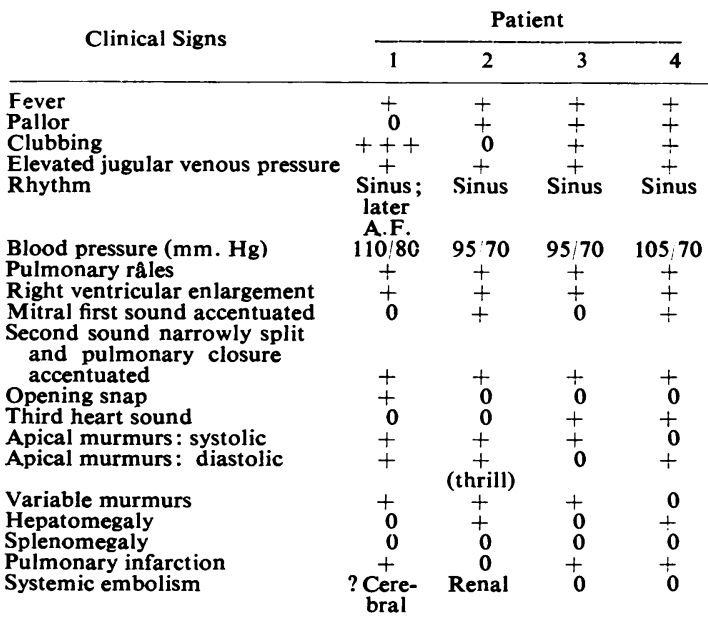

in patients with mitral stenosis in the absence of bacterial endocarditis or other cause. It would be of interest to know whether the bronchial arteries become enlarged in patients with myxoma, but these were not studied in Patient 1 .

Apart from these features suggesting a generalized systemic disorder, the striking signs were in the cardiovascular system. Evidence of pulmonary and left atrial hypertension was present in all, as were signs suggesting mitral valve disease. A diastolic murmur suggesting mitral obstruction was heard in three patients. The murmurs varied from time to time, and pulmonary infarction occurred in three patients.

Undoubted embolism occurred in only one patient, who was in sinus rhythm, and atrial fibrillation in only one other patient.

Phonocardiography (Fig. 13 a-d).-The characteristic features were a widely split first heart sound, a high-pitched pansystolic murmur, and an accentuated pulmonary component of the second heart sound. An opening snap was not recorded, although it had been heard in our first patient. A mid-diastolic murmur was also heard in this first patient, and was both heard and recorded in the fourth patient. In Patient 3 an early diastolic sound was clinically considered to be a third heart sound, but on the phonocardiogram might have been a short mid-diastolic murmur.

The wide splitting of the first heart sound in all patients would be consistent with an enlarged left atrium and delayed filling of the left ventricle due to the space-occupying lesion. The pansystolic murmur was presumably due to mitral incompetence resulting from distortion of the mitral valve by the tumour.

After operation the first heart sound became normal in Patients 3 and 4, the mid-diastolic murmur disappeared in the fourth, and the pansystolic murmur disappeared in the third. Accentuation of pulmonary closure persisted in all patients, and Patient 2 retained the wide splitting of the first sound and a soft systolic murmur.

Owing to the variability of the murmurs, phonocardiography presented some difficulties, and the findings were not always consistent with those on auscultation.

Electrocardiography (Fig. 2).-There were no characteristic features of the disorder, the appearances being those of left atrial and right ventricular enlargement characteristic of any lesion of the left side of the heart producing left atrial and pulmonary arterial hypertension.

The graphs of Patient 1 were of interest, however, in showing no evidence of ventricular imbalance or left atrial embarrassment despite severe pulmonary venous and arterial hypertension.

Radiography OF THE ChEst.-The changes were similar to those found in severe mitral stenosis, with evidence of pulmonary arterial hypertension, enlargement of the right ventricle and main pulmonary arteries, and narrowing of the segmental arteries to the lower portions of the lungs. Pulmonary venous hypertension was shown by horizontal costophrenic lines and hilar shadows suggesting incipient pulmonary oedema.

Pulmonary infarction was present in three patients but disappeared after operation. It was due to obstruction to pulmonary veins, probably by venous thrombosis, rather than to venous occlusion from myxomatous tissue.

The left atrium was enlarged in all the patients, but no intracardiac calcification was seen.

ANGIOCARDIOGRAPHY.- In each patient the examination showed a lobulated filling defect lying in the left atrium. This was least impressive in our first patient, but in the fourth it was obvious, and in different films appeared in the left atrium and left ventricle alternately. This movement of the myxoma through the mitral valve was also seen in Patient 2.

We now regard these appearances as diagnostic of myxoma, for we have never seen them produced by thrombus in a large number of angiograms in mitral valve disease. We consider that a good pulmonary arteriogram should demonstrate a 


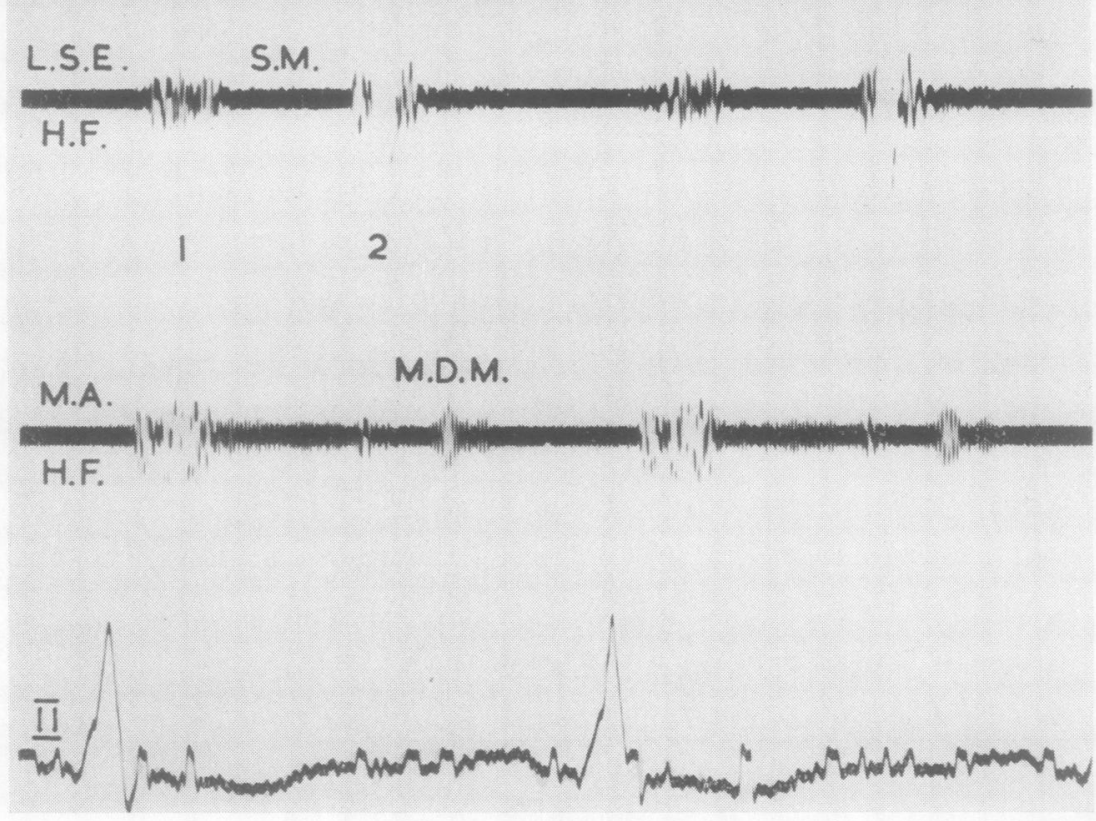

FIG. 13a

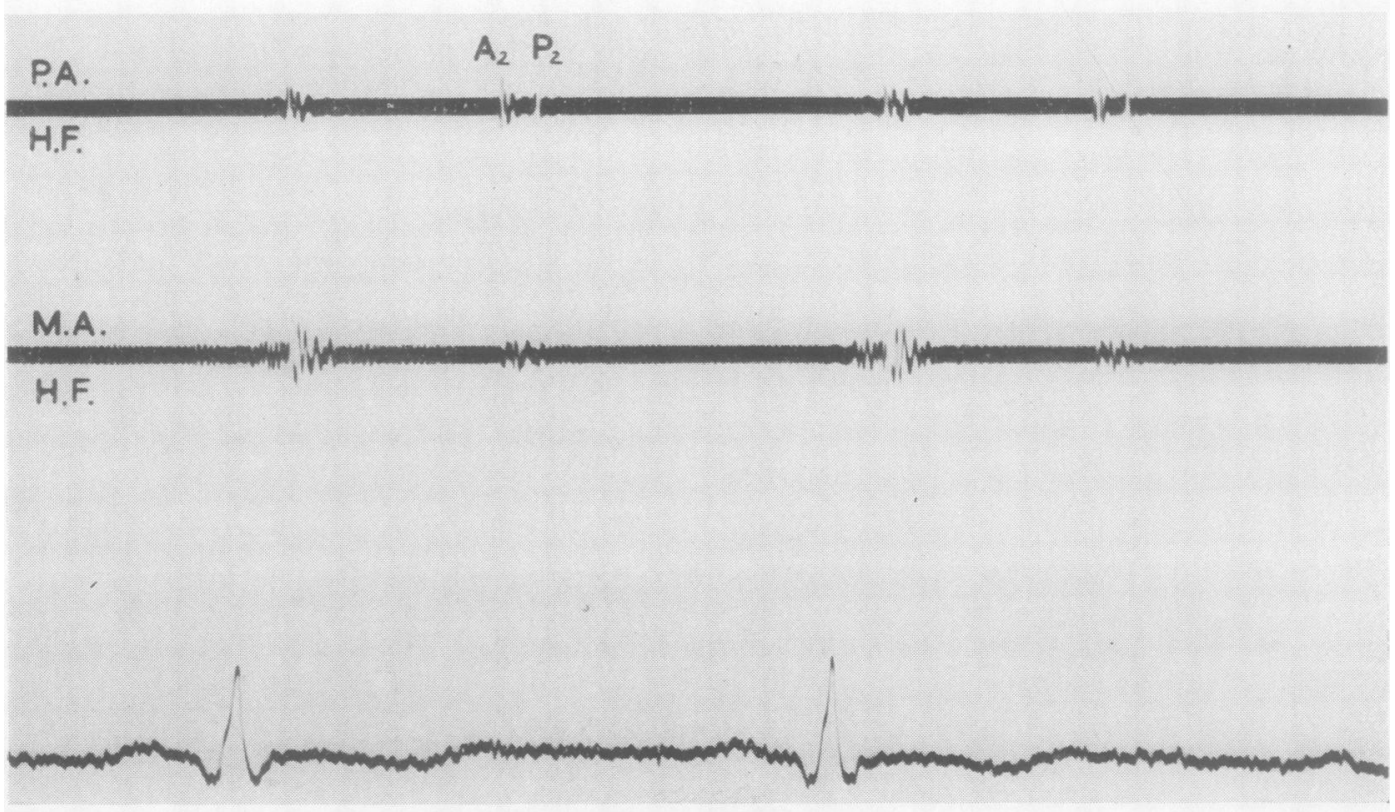

FIG. 13b

FIG. 13.-Phonocardiograms before and after operation: Patient 3 (a) high-frequency recordings from the left sternal edge and mitral area before op ration showing widely split first sound $(0 \cdot 06 / \mathrm{sec}$.), soit pansystolic murmur, and early diastolic vibrations (MDM); pulmonary closure is ascentuated; (b) high-frequency recordings from pulmonary artery and mitral areas after operation: the first heart sound is now single and the diastolic vibrations have disappeared. 


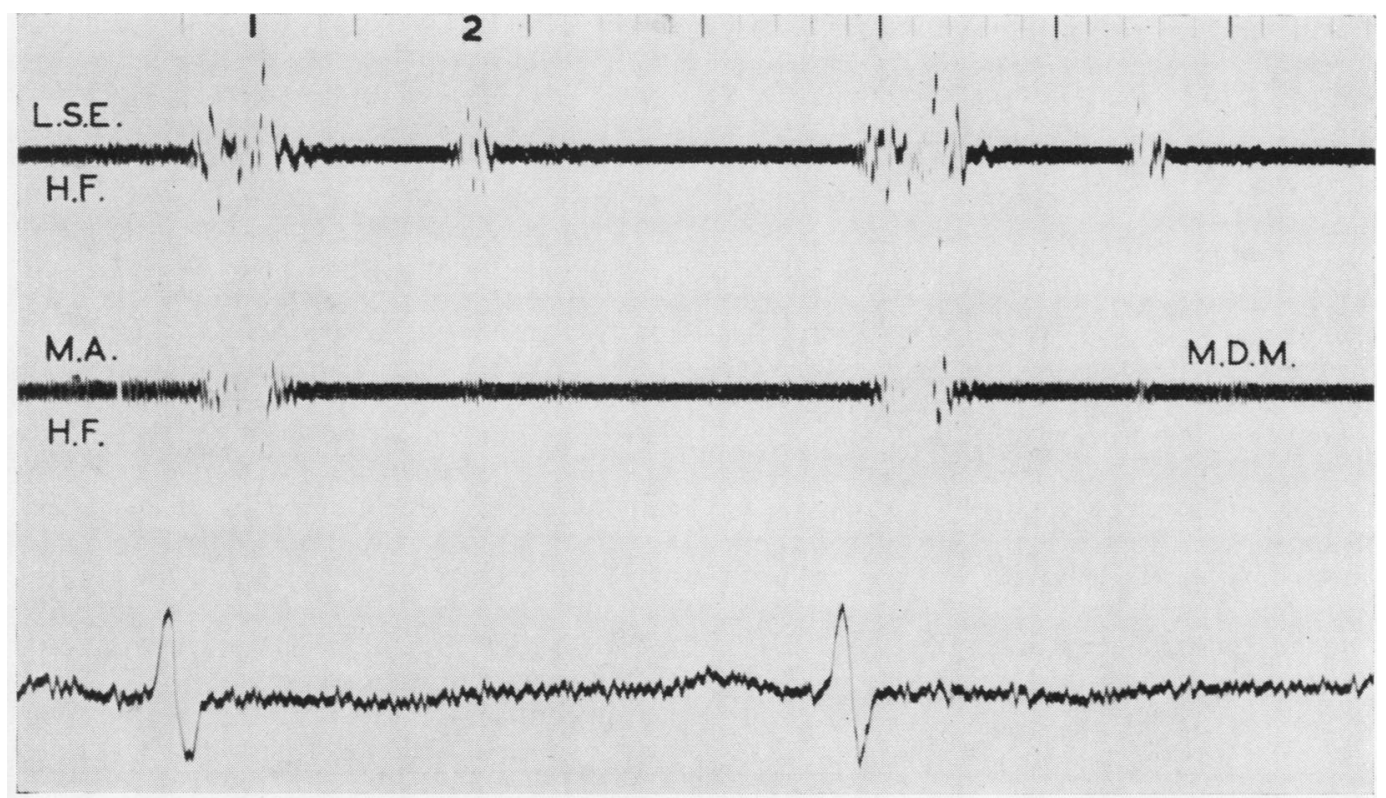

FIG. 13c

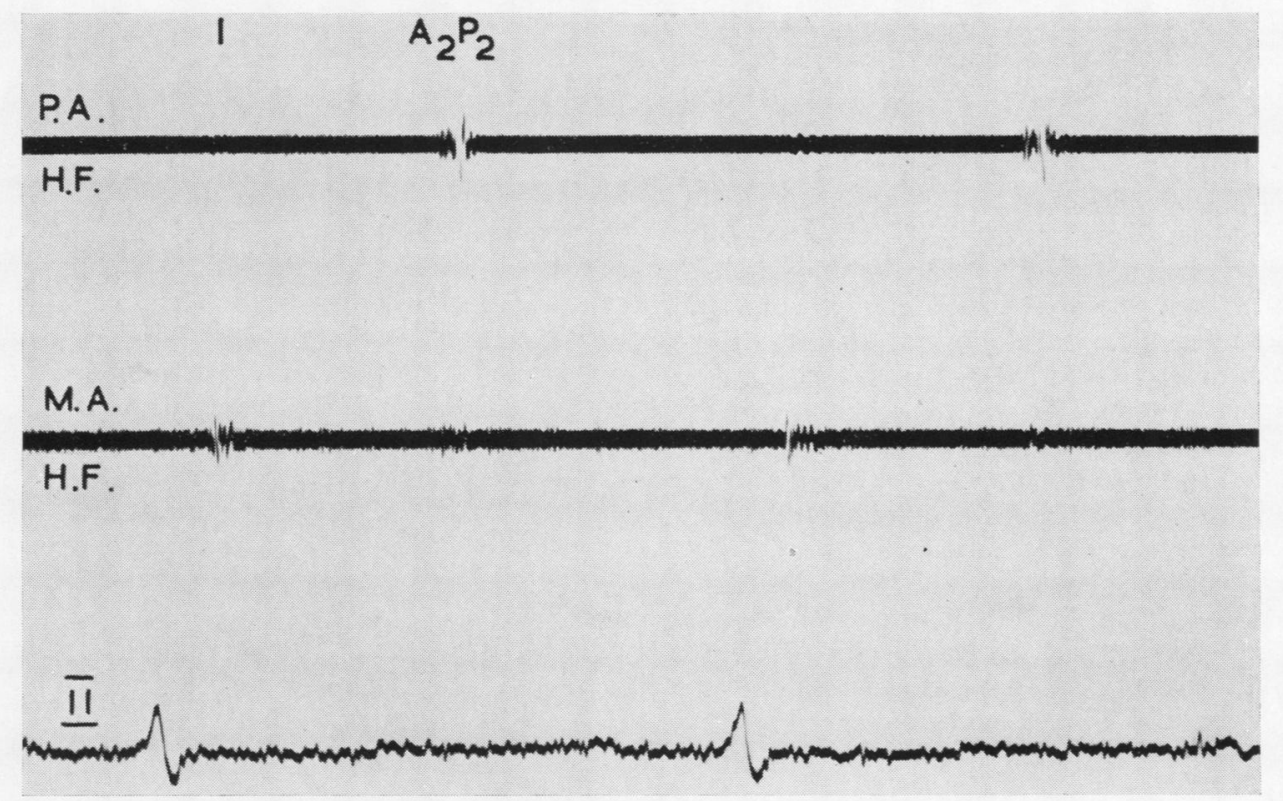

FIG. 13d

FIG. 13.-Phonocardiograms before and after operation: Patient 4 (c) high-frequency recordings from the left sternal edge and mitral area before operation showing widely split first sound $(0.06 / \mathrm{sec}$.) and soft mid-diastolic murmur; pulmonary closure is accentuated; (d) highirequency recordings from pulmonary artery and mitral areas after operation; the first heart sound is now single and the mid-diastolic murmur has disappeared. P.A. $=$ pulmonary artery; M.A. $=$ mitral area; L.S.E. $=$ left sternal edge; H.F. $=$ high frequency; $1=$ first heart sound; 2 =second heart sound; $A_{2}=$ aortic valve closure; $P_{2}=$ pulmonary valve closure. 
myxoma satisfactorily. A left ventricular angiogram is only likely to show the tumour when it is prolapsing into the left ventricle and causing mitral incompetence, as in Patient 2. Passage of the myxoma from left atrium to left ventricle was not shown in the angiograms presented by Goldberg et al. (1952) or by Steinberg et al. (1953).

A further interesting feature was failure to fill the right lower lobe pulmonary veins in two patients ( 1 and 4), probably because of obstruction by thrombus. We thought that the same veins were obstructed in Patient 3 , who also had signs of infarction in the right lower lobe.

We do not know whether obstruction to right lower lobe pulmonary veins is a feature peculiar to myxoma, but it is possible that the tumour obstructs drainage to this lobe. The finding in three of our four cases may well be significant, and should be considered as suspicious of a left atrial myxoma if other features also suggest the condition.

Cardiac Catheterization (Table I).-There were no diagnostic features; the low cardiac output, high pulmonary vascular resistance, and pulmonary arterial venous hypertension were characteristic of severe mitral valve disease. These findings correlated well with the radiological signs. They are of value only in localizing the site of the disorder of the pulmonary circulation to the venous side of the pulmonary vascular bed, and thus suggesting obstruction at atrio-ventricular level.

Radionctive Gas Studies.-Examination with radioactive carbon dioxide labelled with oxygen-15 $\left(\mathrm{C}^{15} \mathrm{O}_{2}\right)$ in two patients showed changes identical with those found in severe mitral stenosis, there being diminished perfusion in the lower portions of the lungs as compared with the upper portions (Dollery and West, 1960).

In both cases, these findings correlated with the radiological appearances of the pulmonary arteries, which were also closely similar to those found in severe mitral valve disease (Doyle, Goodwin, Harrison, and Steiner, 1957). Our studies afforded further information that any lesion which increases left atrial pressure causes constriction of the vessels to the lower lobes of the lungs.

Disorder of Plasma Proteins.-Although abnormal globulins have previously been described in myxoma (Skanse et al., 1959; Evans, 1959 ; MacGregor and Cullen, 1959; and Frankenfeld et al., 1960) sufficient attention has not been paid to this disorder in diagnosis in the past.

All our four patients had increased serum gamma globulins and altered albumin-globulin ratios when studied by paper electrophoresis. The serum albumin was always above 2 g. $\%$ (Fig. 1). From time to time these protein patterns varied considerably quantitatively but remained qualitatively similar, the excessive globulin usually being in the gamma position. They returned towards normal after operation (Fig. 6). In Patient 3 the proteins were initially normal, showing that more than one estimation may be required to detect the abnormalities.

The reason for the abnormal protains is unknown, but we think they are related to the fever, anaemia, raised sedimentation rate, malaise, and loss of weight from which these patients suffered. These features could be explained by a general poisoning of the body tissues by the myxoma, probably by release into the circulation of some abnormal substance; or, less likely, by repeated tiny emboli. The myxoma itself may form excessive or unusual globulin, but there was no qualitative abnormality in the serum gamma globulins, and autoantibodies have not been detected in the patients' blood. Histochemical studies by our colleague, Dr. Everson Pearse, are in progress.

All patients had severe pulmonary arterial and venous hypertension, and this may have been in some way connected with the serum protein disorder. The return of the proteins to normal after removal of the myxoma established beyond question that the tumour was the cause of the protein abnormality.

ANaEmia AND RaISED E.S.R.-All patients had at some time a raised erythrocyte sedimentation rate and variable degrees of anaemia, usually 10 to $12 \mathrm{~g} . \%$ of haemoglobin. The anaemia was nonspecific in type, with slight reduction in mean corpuscular haemoglobin concentration and anisocytosis and microcytosis suggesting iron deficiency or a toxic depression of the bone marrow. Sternal marrow studies in our first patient did not reveal any characteristic abnormality. The white blood cell counts were unremarkable.

Differential Diagnosis from Subacute InfECTIVE ENDOCARDITIS. - The presence of clubbing increases the similarity between myxoma and bacterial endocarditis. Changing "mitral murmurs," emboli, loss of weight, anaemia, fever, sweating, raised erythrocyte sedimentation rate, clubbing, and anaemia are features common to both diseases, and on first examination the differential diagnosis may be impossible. The absence of splenomegaly in our cases of myxoma, and its frequency in infective endocarditis, may provide a useful clue, as may the failure of the 
patient with a myxoma to improve with full chemotherapy for suspected bacterial endocarditis. Repeatedly negative blood cultures do not provide a certain differentiation, for these are not always positive in infective endocarditis (Dormer, 1958 ; Goodwin, 1960) (Table V).

\section{TABLE V}

DIFFERENTIAL DIAGNOSIS OF BACTERIAL ENDOCARDITIS AND LEFT ATRIAL MYXOMA

\begin{tabular}{|c|c|c|}
\hline Clinical Features & $\begin{array}{l}\text { ute Bacterial } \\
\text { ocarditis on } \\
\text { itral Valve }\end{array}$ & $\begin{array}{c}\text { Left } \\
\text { Atrial } \\
\text { Myxoma }\end{array}$ \\
\hline History of rheumatic fever & + c. $50 \%$ & 0 \\
\hline $\begin{array}{l}\text { Rapid progression } \\
\text { Syncope }\end{array}$ & \pm & $\stackrel{\perp}{\perp}$ \\
\hline Systemic emtolism with sinus rhythm & + & + \\
\hline Sinus rhythm & + & + \\
\hline $\begin{array}{l}\text { Atrial fibrillation } \\
\text { Changing murmurs }\end{array}$ & $\stackrel{(+)}{+}$ & $(++)$ \\
\hline $\begin{array}{l}\text { Changing murmurs } \\
\text { Fever }\end{array}$ & + & t \\
\hline Loss of weight & + & \pm \\
\hline Anaemia & + & + \\
\hline High E.S.R. & + & 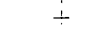 \\
\hline Hyperglobulinaemia & $(+)$ & $i$ \\
\hline Solenomegaly & + & 0 \\
\hline Blood cultures & + usually & 0 \\
\hline Response to antibiotics & & 0 \\
\hline Other valve lesions & + often & 0 \\
\hline
\end{tabular}

Abnormal serum proteins may also occur in infective endocarditis (Flynn, 1954) and in severe and prolonged congestive heart failure.

We accordingly examined all our proven cases of infective endocarditis with positive blood cultures. Unfortunately, in only six had the serum proteins been estimated when the diagnosis had been confirmed by positive blood cultures. Table VI shows that the serum proteins were significantly altered in only three patients, and examination of the electrophoretic patterns in myxoma and bacterial endocarditis by our colleague, Dr. I. D. P. Wootton, did not reveal any qualitative difference between the two conditions.

\section{TABLE VI}

SERUM PROTEINS IN SIX PATIENTS WITH INFECTI VE ENDOCARDITIS AND POSITIVE BLOOD CULTURES

\begin{tabular}{ccc} 
Patient & $\begin{array}{c}\text { Albumin } \\
(\mathrm{g} . \%)\end{array}$ & $\begin{array}{c}\text { Globulin } \\
(\mathrm{g} . \%)\end{array}$ \\
\hline A & $2 \cdot 0$ & $3 \cdot 7$ \\
B & $3 \cdot 6$ & $3 \cdot 9$ \\
D & $3 \cdot 5$ & $3 \cdot 1$ \\
E & $2 \cdot 1$ & $3 \cdot 0$ \\
F & $3 \cdot 0$ & $4 \cdot 1$ \\
& $3 \cdot 85$ & $2 \cdot 85$ \\
& & $4 \cdot 1$
\end{tabular}

We do not believe that the study of the serum proteins contributes to the differential diagnosis of the two diseases, except in so far as normal proteins do not exclude bacterial endocarditis, whereas repeatedly normal proteins would appear to be unlikely in a patient with myxoma.
The differential diagnosis from bacterial endocarditis applies only when evidence of valvular disease other than mitral stenosis or incompetence is absent. The finding of definite aortic valve disease makes a myxoma improbable.

Surgical TechniQue.-Successful removal of left atrial myxoma has been achieved on a number of occasions, and Differding, Gardner, and Roe (1961) in their review quote at least 43 cases. Many authors report only one case, although Cooley, Morris, and Attar (1959) mention three, and Differding et al. (1961) two successful operations using cardio-pulmonary bypass.

Our three patients were operated on using extracorporeal circulation with the Melrose-N.E.P. pump-oxygenator under the supervision of Dr. D. G. Melrose. The flow rate was 2.41 . per square metre of surface area.

The left atrium was approached through the right atrium and inter-atrial septum. This approach was first described by Brock (1956), and we have found it gives direct access to the tumour with an excellent view of its pedicle, thus permitting easy delivery and minimizing fragmentation of the tumour (Fig. 11).

It seems logical to adopt a surgical approach which allows ready identification and complete excision of the tumour pedicle and the related part of the inter-atrial septum.

Gentle delivery of this most friable tumour is essential especially when it is impacted in the ring of the mitral valve. The importance of aortic occlusion during manipulation of the tumour and careful inspection of the left ventricle and left atrium for tumour fragments is emphasized. Thorough lavage of the interior of the heart before closure is important. From the time that the tumour is exposed, use of the normal intracardiac suction apparatus is discontinued and a special sucker is used, the contents of which are discarded.

Vascular Pressures after Removal of the MyхомA.- In each patient there was a fall in left atrial pressure immediately after removal of the tumour, that in the third patient being the most dramatic, the systolic pressure falling to one third of its pre-operative level. As would be expected, the pulmonary artery pressure fell less dramatically, and in Patient 4 there was no significant change. The rise in systemic arterial pressure in Patients 2 and 4 is consistent with a fall in total pulmonary vascular resistance and a rise in cardiac output. The slight fall in pulmonary arterial pressures denies any significant immediate pulmonary vasodilatation and fall in arteriolar resistance, and is consistent with the 
persistence of accentuation of pulmonary valve closure, indicating residual pulmonary hypertension. It is probable that pulmonary vascular disorder, as after mitral valvotomy, will take some time to resolve and that the pulmonary arteriolar resistance will fall slowly.

Pathology. - All four tumours were surprisingly consistent in their pathological features. They all had narrow, rather fibrotic pedicles, and three bore the indentation of the mitral valve ring which distorted the shape and made it possible to delineate an atrial and ventricular portion. They were similar also in that their point of attachment was in each instance to the posterior or postero-inferior margin of the fossa ovalis. The external appearance was that of a lobulated glistening mass with fronds or rounded projections of softer gelatinous, pale yellowish-pink material, which was rather friable, and scattered darker areas of haemorrhage. The overall consistency was rubbery, being somewhat firmer centrally than superficially (Fig. 5).

Each tumour was sectioned through the pedicle and longest length in order to see the disposition of the histological elements. The pedicle was firm and often fibrotic, and in it ran several thickwalled vessels which soon became small capillary channels. The fibrosis extended in frond-like fashion into the main mass, and in this region there were a variable number of haemosiderincontaining macrophages and free pigment. This was most evident in Patient 1.

The main tumour mass consisted of a pale, myxomatous stroma, scattered in which were the somewhat embryonic cells, stellate in shape and with cytoplasmic processes, usually singly or in small groups forming syncytia. A few small capillaries were present, and haemorrhage around them was not uncommon. Fine strands of elastic tissue were also present, but mainly in the region of the blood vessels in the pedicle. The endothelial lining of the atrium was continuous over the whole of the surface of the tumour, and this surface layer of cells was very similar to the cells comprising the main mass. Some cells were multinucleate, but there were no mitoses. The underlying atrial wall was normal (Fig. 3).

\section{Discussion}

It is apparent from our four patients, and from the additional patient described from this hospital by MacGregor and Cullen in 1959, that the combination of signs of pulmonary venous and arterial hypertension with apical murmurs of a changing character and signs of a general systemic disorder with fever, anaemia, or abnormal serum proteins and raised erythrocyte sedimentation rate is highly suggestive of a left atrial myxoma.

Three comprehensive retrospective reviews of atrial myxoma have recently appeared, dealing mainly with cases diagnosed for the first time at operation or at necropsy (Campeau and David, 1960 ; Aldridge and Greenwood, 1960 ; Differding et al., 1961). Campeau and David reported 65 myxomas (57 in the left atrium) collected over a period from January, 1954, to January, 1959. Aldridge and Greenwood published an analysis of 32 cases of left atrial myxoma reported in the literature, and added three of their own. Presumably some of the same cases have been reported in both these papers. Campeau and David reported that eight of their cases $(18 \%)$ had resembled bacterial endocarditis with loss of weight, fever, petechiae, and raised sedimentation rate, but no splenomegaly and negative blood cultures. Differding et al. stressed that embolic phenomena and fever might suggest bacterial endocarditis. Aldridge and Greenwood, in listing the manifestations in their cases, did not mention any features which suggested general systemic disease or infection. The commonest symptoms were the usually accepted ones of shortness of breath, right-sided heart failure, pulmonary oedema, paroxysmal nocturnal dyspnoea, and systemic embolism. Syncope was comparatively uncommon and occurred in only four of the cases. Aldridge and Greenwood, however, stated that blood cultures were carried out in ten cases and were negative, but the reason for taking the cultures was not clear from the original case reports.

Despite reports in the literature of abnormal serum proteins in some patients, this feature has not previously been stressed. Serum protein estimations have been reported in ten patients with myxoma (Martin, 1953 ; Morton, 1954 ; Davis and Andrus, 1954 ; Lekisch, 1957 ; Skanse et al., 1959 ; Evans, 1959 ; MacGregor and Cullen, 1959; Frankenfeld et al., 1960 ; Aldridge and Greenwood, 1960), and in five of these there has been an abnormal albumin-globulin ratio and hyperglobulinaemia. The patient reported by MacGregor and Cullen (1959) had macroglobulinaemia. Fever is mentioned as occurring in 14 of 65 patients reported by Campeau and David (1960).

The importance of signs of an infective or general systemic disorder in arriving at an accurate diagnosis has already been stressed. The other features of the disease, such as changing mitral 
murmurs, third heart sound, and opening snap in a small proportion of cases, are well recognized and do not need further emphasis. The short history of the disease and rapid onset of severe pulmonary hypertension and heart failure are emphasized by Aldridge and Greenwood (1960) and are borne out by our patients. Data obtained at cardiac catheterization revealed evidence of pulmonary arterial and venous hypertension resembling mitral valve disease of a serious degree. We are not aware of any previous mention of a widely split first heart sound, and believe that this may possibly be of some value in diagnosis. We do not know whether occlusion of the right lower lobe pulmonary veins with consequent pulmonary infarction in the right lower lobe is of diagnostic significance, but its occurrence in three of our four patients leads us to regard it as a possible clue to left atrial myxoma in the future.

The features of myxoma may indeed be protean, for ischaemic heart disease may occur in addition to pulmonary hypertension, systemic embolism, and general systemic disorder. Harvey (1957) reported cardiac infarction due to coronary embolism, and Dr. D. H. Davies, of Bristol, has shown us two patients with myxoma and coronary embolism. Myxoma should therefore be considered in the differential diagnosis of a patient with unusual features of cardiac ischaemia.

The definitive diagnosis of myxoma is made by adequate selective angiocardiography. We believe that the lobulated nature of the filling defect is characteristic. Its passage between atrium and ventricle is also important and has not previously been stressed.

Accurate diagnosis is clearly of great importance, for the record of successful treatment is not good. Only 13 of 38 patients operated upon for atrial myxoma were diagnosed correctly before an operation for embolectomy or valvotomy (Differding et al., 1961). Campeau and David (1960) reported that of 45 left atrial myxomas only four were suspected clinically, and three confirmed by angiocardiography, while 16 were discovered accidentally during surgery for mitral stenosis, and 22 were diagnosed at necropsy.

Previous reports, and the progress so far of our three patients from whom the tumour has been successfully removed, suggest that this condition is completely curable when treated in the correct fashion. Untreated it leads inexorably to a fatal outcome.

Of a total of 66 patients with left atrial myxoma reported by Gleason (1955) and by Campeau and
David (1960), 13 were suspected of having infective endocarditis, and the differential diagnosis between this condition and myxoma is therefore of real importance.

We consider that the condition should be suspected in any patient without a history of rheumatic fever and without evidence of other valve disease, who presents a rapid downhill course with loss of weight, signs of general systemic disease, abnormal serum proteins, fever, and signs of mitral valve obstruction with pulmonary hypertension. As with mitral valve disease, myxoma appears to be more common in women; of the 35 cases reported by Aldridge and Greenwood (1960), 26 were women and only nine were men. This agrees with our own finding of three women and one man.

Absence of a history of rheumatic fever is of little value in diagnosis, for approximately $50 \%$ of patients with mitral stenosis have no history of rheumatic fever, while a history of rheumatic fever has been reported in a patient with myxoma (Belcher, 1958).

Myxoma and mitral valve disease may co-exist (Marions and Ödman, 1957; Aldridge and Greenwood, 1960), while myxoma developing in a patient who had previously had a valvotomy for mitral stenosis has been documented by Deshmukh, Nichols, and Goldberg (1959).

\section{CONCLUSIONS}

As a result of our experience, we believe that left atrial myxoma may now readily be suspected clinically, proven radiologically, and cured surgically. Clinical suspicion, however, should arise less from embolic and haemodynamic features than from signs and symptoms suggesting generalized inflammatory disease in a patient with pulmonary hypertension, heart failure, or signs suggesting mitral valve disease.

\section{SUMMary}

Four patients with myxoma of the left atrium are described. The diagnosis was made correctly in all four without the aid of surgery or necropsy, and in the three who came to surgery the tumour was successfully removed.

All patients presented with rapidly progressive cardiac illness, severe pulmonary hypertension, and signs suggesting mitral valve disease. They all showed abnormalities in the serum proteins, consisting of elevation of the globulin factors, usually in the gamma position. Bacterial endocarditis was closely simulated in two patients, and subacute rheumatic fever in one. 
The clinical picture, results of special investigations, diagnosis, and surgical treatment are described. Special emphasis, hitherto not reported, has been paid to the serum protein disorder in diagnosis, and the differentiation from bacterial endocarditis is discussed.

We are grateful to Mr. W. P. Cleland and to $\mathrm{Dr}$. R. S. Bruce Pearson for kindly referring Patient 4 and to Drs. D. H. Davies and D. W. Barritt for Patient 3. We are also indebted to Mr. Cleland and to Mr. L. L. Bromley for allowing us to quote their operation notes. Dr. Arthur Hollman kindly performed the left ventricular angiogram in Patient 2 and took the operation photograph (Fig. 11).

\section{REFERENCES}

Aldridge, H. E., and Greenwood, W. F. (1960). Brit. Heart J., 22 189.

Belcher, J. R. (1958). Brit. J. Tuberc., 52, 62.

Brock, R. C. (1956). Guy's Hosp. Rep., 105, 382

Campeau, L., and David, P. (1960). Canad. med. Ass. J., 82, 586.

Cooley, D. A., Morris, G. C., and Attar, S. (1959). A.M.A. Arch. Surg. 78, 410.

Davis, F. W., and Andrus, E. C. (1954). New Engl. J. Med. . 251, 297

Deshmukh, M., Nichols, H. T., and Goldberg, H. (1959). Amer. Heart J., 58, 623 .

Differding, J. T., Gardner, R. E., and Roe, B. B. (1961). Circulation, 23, 929 .
Dollery, C. T., and West, J. B. (1960). Circulation Res., 8, 765.

Dormer, A. E. (1958). Brit. med. J., 1, 63.

Doyle, A. E., Goodwin, J. F., Harrison, C. V., and Steiner, R. E. (1957). Brit. Heart J., 19, 353.

Evans, W. (1959). Ibid., 21, 197.

Flynn, F. V. (1954). Proc. roy. Soc. Med., 47, 827.

Frankenfeld, R. H., Waters, C. H., and Steiner, R. C. (1960). Amn. intern. Med., 53, 827.

Gleason, I. O. (1955). Cancer, 8, 839.

Goldberg, H. P., Glenn, F., Dotter, C. T., and Steinberg, I. (1952). Circulation, 6, 762.

Goodwin, J. F. (1960). Proc. roy. Soc. Med., 53, 556.

Harvey, J. C. (1957). Ann. intern. Med., 47, 1067.

Leach, W. B. (1947). Arch. Path. (Chicago), 44, 198.

Lekisch, J. (1957). Ann. intern. Med., 46, 982

MacGregor G. A and Cullen. R A (1959). Brit med J., 2, 991.

Marions O. G. Ä Ödman P. (1957). Acta radiol. (Stockh), 47, 461.

Marions. O., and Odman, P. (1957). Acta radiol.

Martin, B. F. (1953). Ann. intern. Med., 38, 325.

Morton, E. V. B. (1954). Edinb. med. J., 61, 227.
Prichard, R. W. (1951). A.M.A. Arch. Path.. 51, 98.

Skanse, B., Berg, N. O., and Westfelt, L. (1959). Acta med. scand., $164,321$.

Steinberg, I., Dotter, C. T., and Glenn, F. (1953). Dis. Chest, 24, 509.

\section{ADDENDUM}

Since writing this paper we have become aware of a report of hypertrophic osteoarthropathy in a patient with a primary rhabdomyosarcoma of the heart (Pascuzzi, C. A., Parkin, T. W., Bruwer, A. J., and Edwards, J. E., Proc. Mayo Clin., 1957, 32, 30). 